\title{
Full-field Measurement of Residual Strains in Cold Bent Steel Plates
}

\author{
E.J. Gerbo ${ }^{\text {a }}$, A.P. Thralla,*, B.J. Smith ${ }^{\mathrm{a}}$, T.P. Zoli ${ }^{\mathrm{b}}$ \\ ${ }^{a}$ Kinetic Structures Laboratory, Department of Civil and Environmental Engineering and Earth Sciences, \\ University of Notre Dame, 159 Fitzpatrick Hall, \\ Notre Dame, IN 46556, USA \\ ${ }^{b}$ HNTB Corporation, 57th Floor, Empire State Building, 350 5th Ave, \\ New York, NY 10118, USA
}

\begin{abstract}
With the recent American Association of State Highway and Transportation Officials bridge design code acceptance of cold bent fracture-critical and nonfracture-critical plates and the increasing use of cold bending by the bridge industry, there is a need to better understand and predict residual strains in cold bent steel. However, measuring residual strains is a challenging task since the bending process typically interferes with conventional instrumentation. This paper introduces three-dimensional Digital Image Correlation (DIC) as a new, non-destructive approach to measuring residual strains in cold bent steel that captures fullfield strain data with high accuracy. DIC was used to measure residual strains in 18 cold bent $12.7 \mathrm{~mm}$ thick ASTM A36 steel plates, bent using a press-brake to a constant radius of $102 \mathrm{~mm}$ with varying angles (10, 20, and 30 degrees) and plate widths $(76.2 \mathrm{~mm}$ and 203 $\mathrm{mm})$. The measured residual strains are compared to analytical predictions and both twoand three-dimensional finite element models. A parametric study, using the validated finite element models, is completed for additional widths $(12.7 \mathrm{~mm}$ and $140 \mathrm{~mm})$ and thicknesses $(6.35 \mathrm{~mm}$ and $19.1 \mathrm{~mm})$ to investigate the effect of these parameters on circumferential strains, contact pressure, strain state, and to make modeling recommendations. Results are used to develop a means of predicting peak residual strains based on the final plate dimensions - a useful quality control measure.

Keywords:

Residual strain, Cold bending, Digital image correlation
\end{abstract}

\section{Introduction}

Understanding residual effects in cold bent steel is critical since the residual stresses and strains vary through the cross-sectional thickness, as opposed to residual effects from hot rolling for which there is little through-thickness variation. The variation in residual stresses

\footnotetext{
${ }^{*}$ Corresponding author

Email addresses: egerbo@nd.edu (E.J. Gerbo), athrall@nd.edu (A.P. Thrall), bsmith24@nd.edu (B.J. Smith), tzoli@hntb.com (T.P. Zoli)
} 
is particularly important in building applications (in which thin-walled cold formed sections are typically used) as these affect a member's load-displacement behavior and ultimate strength due to early yielding at plate faces $[1,2]$. In the bridge industry (in which thick plates, including plates of built-up members, are typically bent) the primary concern is that strains induced from bending can result in cracking on the outer, tensile face of a bend as a result of the reduced ductility of plastically deformed steel (including the effect of strain aging) [3]. This reduction in ductility has been studied extensively and has been found to be related to the magnitude of plastic strain $[4,5]$. Due to this behavior, the bridge industry has significantly lagged behind the building industry in the implementation of cold formed steel [6] despite potential cost and time savings [7]. The American Association of State Highway and Transportation Officials (AASHTO)/National Steel Bridge Alliance (NSBA) Steel Bridge Fabrication Guide Specifications and the AASHTO Load and Resistance Factor Design (LRFD) Bridge Construction Specifications (up until a 2012 interim revision) did not permit cold-bending of fracture-critical steels and members [8-10]. However, based on the findings of Keating and Christian (2012) [8], the 2012 interim revision of AASHTO LRFD Bridge Construction Specifications has changed this stipulation such that fracturecritical and nonfracture-critical plates should be cold bent [11]. Through testing tensile steel samples at room temperature and subjected to heat conditions similar to that which would be used for heat-assisted bending of steel, Keating and Christian (2012) [8] found that cold bending is preferred over heat-assisted bending as the heat-assisted bending led to reduced ductility and contributed to cracking. They also found that strains exceeding 10 percent result in reduced fracture toughness through Charpy V-Notch tests [8]. This strain corresponds to a limiting bend radius of approximately $5 t$ (where $t$ is the plate thickness, using an analytical prediction for strain - see Equation 3 and related discussion) which is the limit prescribed in the 2012 interim revision of AASHTO LRFD Bridge Construction Specifications [11].

Recent applications of cold bending in bridges include flanges of built-up girders to achieve a shallower cross-section (i.e., dapped girder) at supports [8, 12], flanges of the Memorial Bridge between Portsmouth, NH and Kittery, ME (USA) to achieve a truss without gusset plates [13], and curved girder bridges [6, 14-16]. Bent plates have also been used for connections of large skewed bridges [17]. With this new interest for bridge applications and recent changes to design code, this research is focused on understanding residual strains from cold bending steel plates. Measured residual strains are compared to existing analytical predictions and to both two- and three-dimensional (2D and 3D, hereafter) finite element (FE) numerical models. A parametric study, using the validated numerical models, is performed for additional widths [12.7 mm (0.5 in.) and $140 \mathrm{~mm}(5.5 \mathrm{in})$.$] and thicknesses$ [6.35 mm (0.25 in.) and $19.1 \mathrm{~mm}$ (0.75 in.)] to investigate the effect of these parameters on the circumferential strains, contact pressure, and strain state. These studies culminate in modeling recommendations to predict residual strains in a design environment. Furthermore, cold bending may occur in scenarios where the bend radius (a parameter used for predicting peak residual strains and the limiting metric used in AASHTO LRFD Bridge Construction Specifications [11]) is unknown or not clearly defined. This paper develops a means of predicting peak residual strains based on the post-bend plate dimensions. This is a useful quality control measure, as fabricators and contractors could readily determine if the residual strains exceed the 10 percent limit suggested by Keating and Christian (2012) 
[8].

Further, measuring residual strains in a laboratory environment is a challenging task since the bending process typically interferes with conventional instrumentation (e.g., strain gages). Surface strains can be measured by scribing a grid on the sample prior to bending then measuring distances between grid lines after bending as described by Brown and Jones (1946) [18] and as implemented by Sangdahl et al. (1948) [19], Karren (1967) [5], and Weng and White (1990) [20], among others. However, the gage length must be determined a priori. This length should be chosen to be sufficiently small so that local variations in strain can be observed and sufficiently large so that accuracy is not lost (here, accuracy is inversely related to the gage length) [18]. Furthermore, the accuracy of this approach is limited due to inaccuracies in the grid applications and inaccuracies in measuring the strains (which can be particularly challenging along curved surfaces) [18, 19]. In addition to using a grid method, Weng and White [20] used high-elongation strain gages for tighter bend radii, with grooves cut into the dies to facilitate the gages and associated wiring. However, this method requires specially fabricated dies. Further, there is an extensive body of research focusing on the impact of cold-forming on material properties and behavior of members, including hollow structural sections (HSS, e.g., [21-23]), channels (C-shapes, e.g., [24-29]), angles (L-shapes, e.g., [30]), and hat-shaped sections (e.g., [24, 28]). Note that this is a non-exhaustive review of this research.

This paper introduces 3D Digital Image Correlation (DIC) as a new approach to measuring residual strains in cold formed steel. DIC is a non-destructive, photographic measurement technique that captures full-field displacements and strains (see Subsection 4.2 for full description). DIC improves on the deficiencies of the grid method as the gage length can be adjusted during post-processing, it is capable of measuring displacements and strains around curves, and it offers higher accuracy. It improves upon strain gage methods which only provide data at distinct points (potentially missing a nearby high stress concentration), and cannot capture strain gradients [31]. This paper harnesses this full-field residual strain data to validate FE numerical models, compare with simplified analytical predictions, and ultimately develop a quality control measure for cold bending.

\section{Objectives and Scope}

The objective of this research is to study full-field residual strains induced from cold bending. The full-field behavior of 18 [12.7 mm (0.5 in.)] thick ASTM A36 steel plates (Table 1), bent using a press-brake (Figure 1 and 2) to a constant radius $(r)$ of $102 \mathrm{~mm}$ (4.0 in.) with varying angles $\left(\theta=10^{\circ}, 20^{\circ}\right.$, and $\left.30^{\circ}\right)$, is measured experimentally using $3 \mathrm{D}$ DIC. Measured results are compared to analytical predictions and with both $2 \mathrm{D}$ and $3 \mathrm{D}$ FE numerical models, culminating in recommendations for predicting residual strains in a design environment. A parametric study using validated FE models is performed to further extend the conclusions to varying width and thickness plates. This paper then develops a method for predicting peak residual strains based on post-bend plate dimensions as a quality control measure for contractors and fabricators. 


\section{Material Properties}

Material testing was performed according to ASTM standards [32-35] using an Instron 5590 Universal Testing Machine to determine appropriate material properties for FE modeling. Material samples were sized according to ASTM recommendations [33] for a $50.8 \mathrm{~mm}$ (2 in.) gage length at full $[12.7 \mathrm{~mm}(0.5 \mathrm{in}$.) $]$ thickness. Samples were oriented so that the longitudinal axis is parallel to the final direction of rolling, as per ASTM recommendations [32]. This also corresponds to the direction perpendicular to the axis of the bend in this research. Samples were taken from two different bars, as per ASTM recommendations [32]. The results from 8 samples (all of which broke in the gage region) are summarized in Table 2. The yield strength shown in this table was obtained using the $0.2 \%$ offset method, as per ASTM recommendations [33]. This method consists of creating a line parallel to the elastic region, with a strain offset of $0.002(0.2 \%)$. The point where this offset line and the measured stress-strain intersect is considered the yield stress. Young's modulus for each sample is taken as the slope of a best fit line, fit using the least squares method, applied to the stress-strain relationship in the elastic region, per ASTM recommendations [34]. For these calculations, strain was measured via an Instron Model 2630-114 extensometer with $50.8 \mathrm{~mm}$ (2.0 in.) gage length and engineering stress was calculated based on the known area and force measured by the Universal Testing Machine. Poisson's ratio was determined as the slope of a best fit line in the elastic range of the axial strain to transverse strain relationship, per ASTM recommendations [35]. Measurements for this calculation were from strain gages (EA-06-125BZ-350/E, MicroMeasurements) applied to the sample in both axial and transverse directions. A representative stress strain relationship from one sample is shown in Figure 3.

\section{Experimental Program}

\subsection{Plate Samples}

A total of 18, $12.7 \mathrm{~mm}$ (0.5 in.) thick A36 steel plate samples (Table 1) were bent to a $102 \mathrm{~mm}$ (4 in.) radius $(r)$ - equivalent to $8 t$, where $t$ is the thickness of the plate - using a press brake (Figure 1). All plate samples are the from the same heat of steel, as are the material samples. The bend radius was chosen as it exceeds the minimum bend radius of $5 t$ (for bend axes perpendicular to the final direction of rolling) for cold bent plates prescribed by the AASHTO LRFD Bridge Construction Specifications 2012 interim revisions [11] based on the findings of Keating and Christian [8]. Samples were bent to angles $(\theta)$ of $10^{\circ}, 20^{\circ}$, and $30^{\circ}$ to investigate the effect of bend angle on residual strains. The coin dies used in the press-brake have a maximum theoretical bend angle of $68.5^{\circ}$ before elastic spring-back is taken into consideration. Half of the samples were nominally $76.2 \mathrm{~mm}$ (3 in.) wide and the other half were $203 \mathrm{~mm}$ ( 8 in.) wide to investigate the effect of width-to-thickness ratio on residual strains.

\section{2. $D I C$}

The residual strains in the bent plates were measured by a 3D DIC system (Figure 4). The DIC system used in this study (provided by Trilion Quality Systems) consisted of two cameras [2448 x 2050 pixels, $12 \mathrm{~mm}$ (0.472 in.) manual focus lenses] and utilized 
ARAMIS DIC software [36] to measure surface displacements and strains of a sample within the "field-of-view" (FOV). The FOV for this application is approximately $610 \mathrm{~mm}(24 \mathrm{in}$.) to capture the full plate size. A random pattern [circular and elliptical shapes on the order of $1 \mathrm{~mm}$ (0.04 in.) diameter so that each shape is approximately 5 pixels in diameter] was applied on the surface of each plate by first coating the surfaces with CerMark LMM-6000 Metal Laser Marking Spray [37] and then etching the pattern using a laser cutter (Universal Laser Cutter, VLS 6.60, $50 \mathrm{~W}$ laser). Stereo pairs of photographs were captured before and after the plate bending process on all four faces of each plate. The captured digital images were divided into pixelated regions called facets which are 17 by 17 pixel squares. Using pattern recognition and photogrammetric triangulation principles, these facets were tracked through a complete image series to yield 3D full-field surface strains. The system is capable of measuring displacements to $1 / 30,000$ of the FOV [31, 38]. For this study, this corresponds to an accuracy of the displacements of \pm 20.3 microns $\left( \pm 8.00 \times 10^{-4} \mathrm{in}\right.$.). This accuracy, however, refers only to the facet matching. Additional sources of error include camera signal-to-noise ratio and dark current [39]. To characterize the amount of noise in the strain measurements, pre-test analyses - in which 3 photos were taken without moving or loading the sample and image correlation was performed - were undertaken, finding noise of approximately 1000 micro-strain. Compared to the peak strain found in this research (76,000 micro-strain), this noise is roughly 1.4 percent of the peak strain observed in this study.

DIC has become a widely used system for measuring strain and displacement. The reader is referred to Pan et al. (2009) [40] and Orteu (2009) [41] for reviews of this technology and its applications. Applications in structural engineering are reviewed by McGinnis et al. (2012) [42] and McCormick and Lord (2012) [43] and include investigations of the behavior of reinforced concrete walls [44, 45], reinforced and unreinforced masonry walls [46], wood buildings [47], bridges [48-53], and fiber-reinforced polymer confinement coverings for concrete columns [54], among others.

Most relevant for the research presented here, DIC has previously been used to determine residual stresses. Nelson et al. (2006) [39] and Lord et al. (2008) [55] have demonstrated the use of DIC to measure residual strains with the semi-destructive hole-drilling method [56]. This approach overcomes the drawbacks of the conventional method for measuring strains with strain gage rosettes which include the time for precise installation for rosettes, errors which result if the hole is drilled off-center with respect to the rosette, and errors from measurement of thermally-induced strains during the drilling process $[39,55,57,58]$. This work was performed on shrunk fit aluminum alloy plugs inside steel and aluminium rings using 3D DIC [39] and shot-peened aluminum using 2D DIC [55]. Algorithm development for improved accuracy of DIC measurements used with the hole-drilling method has also been performed by Gao and Shang (2009) [57] and Baldi (2014) [58, 59]. The reader is referred to Schajer (2010) [60] for a review of DIC used for residual stress measurement by hole-drilling, including comparisons to other methods. McGinnis et al. (2005) [61] used DIC to measure in-situ stresses of concrete structures determined by the core-drilling method (similar to holedrilling, but measuring displacements instead of strain). DIC has also been coupled with the ring-core method for determining residual stress [62]. This existing literature utilizes DIC to measure residual stresses using semi-destructive stress-relief approaches at a local region (i.e., where a hole, core or ring is drilled). In contrast, this work is focused on measuring 
residual strains imparted by cold bending as this is the primary metric limited by bridge design code (through minimum bend radii requirements) based on recommendations related to reduced ductility and fracture toughness.

\section{Numerical Modeling}

While many studies have presented methods for numerical modeling of cold-formed steel sections (e.g., Schafer et al. (2010) [63], Schafer and Pekoz (1998) [1], and Li and Cescotto (1997) [64]), only a limited number of FE studies have focused on the behavior during the cold bending process. Rossi et al. (2013) [65] investigated thin-walled cold-formed steel channels during the cold fabrication process and presented improved modeling techniques for predicting the modified stress strain relationship due to material nonlinearity. Rossi et al. (2013) [66] focused on predicting the modified yield stress and ductility of cold-formed structural steel sections that undergo plastic deformations during cold bending. Keating and Christian (2012) [8] studied both cold and heat assisted bending, culminating in the recent revisions to bridge design code permitting cold bending.

Other past numerical research has focused on predicting the residual stresses during the cold bending process, including FE based methods for predicting residual stresses in pressbraked thin-walled sections $[67,68]$ as well as curved structural wide flange steel sections [69]. Other studies have explored the relationship between hardness and residual strain [70], including an FE approach used to relate measured hardness and predicted equivalent plastic strains in cold-formed V-band clamps manufactured from initially flat strips [71].

The work presented in this paper differs from these previous studies in that the numerical models used to predict residual strains are validated against full-field strain data, a significant advancement in the understanding of the behavior during the cold bending process. 3D FE models were developed to be able to compare with the full field measured results on all four faces of the bent plates. Results are also compared to faster running, simplified 2D FE models to develop recommendations for analysis in a design environment.

2D and 3D FE models of the bending process were built in the software package ABAQUS/ Standard [72], which utilized implicit analysis. In both 2D and 3D models, the press brake dies were modeled as analytically rigid surfaces. Contact surfaces between the plate and the dies were assumed to be frictionless. The interaction was modeled as "hard" contact in the normal direction and allows for separation after contact. Nonlinear geometry was enabled to account for the large deformations during the bending process. Note that the self-weight of the plates was ignored, as the effect of self-weight is negligible compared to the pressing action. The 2D models used CPE4R plane strain continuum elements (assuming a plane strain state) while the 3D models used C3D8R solid continuum elements. A mesh size of $0.794 \mathrm{~mm}$ (0.0313 in.) was chosen for both the 2D and 3D models based on the results of a mesh refinement study. This results in 16 element layers through the thickness of the plate.

A non-linear material model was implemented based on the results of the material testing (Table 2, Figure 3). The engineering stress strain relationship is composed of strain measured by an extensometer and stress calculated from the force in the testing machine divided by the original measured cross sectional area. Non-linear material models in ABAQUS require the true stress strain relationship. This can be readily calculated using known relationships: 


$$
\begin{gathered}
\epsilon_{t}=\ln \left(1+\epsilon_{e}\right) \\
\sigma_{t}=\sigma_{e}\left(1+\epsilon_{e}\right)
\end{gathered}
$$

where $\epsilon_{t}$ is the true strain, $\epsilon_{e}$ is the engineering strain, $\sigma_{t}$ is the true stress and $\sigma_{e}$ is the engineering stress [73]. The yield stress used for the FE material model was the average of the yield stress of the 8 samples, calculated via the $0.2 \%$ offset method. The elastic modulus for the FE material model was the average elastic modulus of the 8 samples. The stress strain relationship was considered a plateau after the yield stress until the onset of strain hardening. At the transition between the yield plateau and the strain hardening region, the measured data shows a slight drop in stress before experiencing strain hardening; this was ignored in the FE material model for simplicity. After the yield plateau, the strain hardening region was modeled as the average true stress of the 8 samples, taken at true strain values up to $0.200 \mathrm{~mm} / \mathrm{mm}$ (0.200 in./in.) in increments of $0.0100 \mathrm{~mm} / \mathrm{mm}(0.0100$ in./in.). This provides adequate fidelity in the material model to capture the measured stress strain relationship. The strains measured in this study never exceed the strain corresponding to the ultimate true stress, and therefore the descending portion of the stress strain curve was not modeled.

Several steps were required to model the press braking process. For the $2 \mathrm{D}$ models, the horizontal $(x)$ translation of the nodes at the transverse midline $(x=0 \mathrm{~mm})$ was restrained in all steps for stability (see Figure 2 for the coordinate system). For the 3D models, only one quarter of a plate was modeled to minimize computational expense, taking advantage of symmetry about the $x$ and $z$ axes. The plate was cut along the transverse midline $(x=0$ $\mathrm{mm})$, with translation of nodes at $x=0 \mathrm{~mm}$ being restrained in the $x$ direction. The plate was also cut along the longitudinal midline $(z=0 \mathrm{~mm})$, with translation of nodes at $z=0 \mathrm{~mm}$ being restrained in the $z$ direction. These boundary conditions remain for all steps. The first step pressed the top die down into contact with the upper surface of the plate as it was supported by the bottom die. The plate was over-bent to a sharper angle during the pressing step to achieve the final desired angle due to the effect of elastic spring-back. The model was controlled via displacement of the top die, therefore the pressing displacement needed to achieve a final desired angle required iteration. Achieving a final angle within 0.1 percent of the desired angle was deemed acceptable. Note that due to slight variations in the fabrication of the plates the measured bend angles vary slightly from the intended $10^{\circ}, 20^{\circ}$, and $30^{\circ}$ bend angles (see Table 1 ). The desired angles in the FE models were therefore the average measured angle from 3 samples of each configuration (i.e., width and bend angle combination). Once the top dies reached its peak displacement, restraints (i.e., translation restrained in all directions) were added to all nodes to temporarily hold the plate in position as the dies were removed. Spring-back was then allowed to occur by releasing these restraints. To maintain stability, a vertical restraint ( $y$ translation restrained) at the center node $(x=0 \mathrm{~mm}, y=0 \mathrm{~mm}, z=0 \mathrm{~mm})$ was added.

\section{Analytical Predictions}

Measured and numerical results are also compared with simplified analytical predictions for circumferential strains in the literature. Assuming a homogeneous material, plane sections 
remain plane, the neutral axis remains at the plate centerline, and the plate is subject to pure bending, a mechanics-based approach to predicting the circumferential residual strains $\left(\epsilon_{x}\right)$ is:

$$
\epsilon_{x}=\frac{-y}{r+\frac{t}{2}}
$$

where $y$ is the distance from the centerline, $r$ is the inner radius of the bend, and $t$ is the thickness (see coordinate system definition in Figure 2). Negative values indicate compression while positive values indicate tension. This approach is prevalent in the literature and used by Cook (1966) [74], Kervick and Springborn (1966) [73], Karren (1967) [5], Moen et al. (2008) [2], Keating and Christian (2012) [8], among others. As noted by Cook (1966) [74], in plastic bending operations, the neutral axis is shifted toward the compressive face of the plate by around 5\%. Given this assumption, the prediction for the circumferential strain $\left(\epsilon_{x}\right)$ can be modified as follows:

$$
\epsilon_{x}=\frac{-y+0.05 t}{r+0.45 t}
$$

where $y$ is still measured as the distance from the centerline. Johnson and Mellor [75] also suggested an empirical formulation that is relevant for bend angles exceeding $70^{\circ}$ and for width to thickness ratios greater than 10 . Since the bend angles investigated in this paper are not within this range, their formulation will not be considered.

Weng and White (1990) [20] compared measured peak (surface) circumferential strains with predictions from Equation 3, Equation 4, and that presented in Johnson and Mellor [75], finding that Equation 4 most closely matched the experimental data. However, this study was limited to only considering the top and bottom plate surface strains. The novelty of the research presented here is that the full through-thickness circumferential strain on each plate side can be compared with these analytical predictions.

\section{Results}

\subsection{Validating Finite Element Models}

This section compares the measured and FE numerical circumferential and transverse strains on the compressive and tensile faces of the plate, as well as through the thickness on the sides. Analytical predictions for circumferential strains are also investigated.

\subsubsection{Circumferential Strain Distribution}

Figure 5 compares the measured and FE numerical circumferential strains $\left(\epsilon_{x}\right)$ as a function of the distance $(x)$ along the circumference at the longitudinal midline $(z=0 \mathrm{~mm})$ on the tensile and compressive faces. The 3D FE models are able to closely predict (i.e., 17.0\% average absolute error across all 3D FE data contained in Figure 5) the measured circumferential strains for all samples on both tensile and compressive faces. The 2D models are able to provide similarly close predictions (i.e., $10.9 \%$ average absolute error across all 2D FE data contained in Figure 5). A notable exception to this trend of close agreement is for the $76.2 \mathrm{~mm}$ (3 in.) wide plates with a bend angle of $\theta=30^{\circ}$. Here, the 3D FE model overpredicts the compressive circumferential strains near $x=0 \mathrm{~mm}$ and the $2 \mathrm{D}$ FE model underpredicts 
the tensile circumferential strains near $x=0 \mathrm{~mm}$ compared to the measured data. This can be attributed to (1) the assumption of frictionless interaction between the plate and the dies, and (2) the degree of transverse restraint at the longitudinal midline which affects the location and magnitude of the contact pressure and therefore the friction. Further 3D FE numerical studies that included friction indicated that the peak circumferential strain would be reduced and the strain distribution would widen with the inclusion of friction. This is more pronounced on the compressive face than the tensile face, as would be expected since the compressive face is in contact with the die. This effect is most significant for the plates with the largest bend angles because they have the highest contact pressures, and thus friction plays a more significant role. Including friction for the 3D FE model for the $76.2 \mathrm{~mm}$ (3 in.) wide plates with a bend angle of $\theta=30^{\circ}$ would bring the $3 \mathrm{D} \mathrm{FE}$ numerical results closer to the measured data. As will be discussed further in the parametric study in Section 7.2.1, the magnitude and location of contact pressure (and therefore friction) is affected by the degree of transverse restraint at the longitudinal midline provided by the plate width. Due to the simplifying plane strain state assumption in the 2D FE models, the 2D FE numerical predictions are not able to capture this interaction and therefore do not agree with the 3D FE predictions for narrow plates with large bend angles. The plane strain approximation is adequate for the wider $203 \mathrm{~mm}$ (8 in.) plates that feature significant transverse restraint at the longitudinal midline; however, the narrower $76.2 \mathrm{~mm}$ (3 in.) plates do not provide sufficient transverse restraint to make the plane strain approximation valid. A parametric study was performed to investigate these factors further for different widths and thicknesses as discussed in Section 7.2.2, ultimately culminating in modeling recommendations for a design environment.

The through-thickness circumferential strains measured on the plate sides $(z= \pm w / 2$, where $w$ is the plate width, Figure 6) demonstrate close agreement in the middle of the plate between the measured values and the 2D [i.e., $10.8 \%$ average absolute error in the middle $6.35 \mathrm{~mm}$ (0.25 in.) of the plate] and 3D FE models [i.e., 12.4\% average absolute error in the middle $6.35 \mathrm{~mm}$ (0.25 in.) of the plate]. The close agreement is also shown by the similar slopes of the FE results compared to the measured DIC results near the plate centerline. Note that the measured data near plate edges $(y= \pm t / 2)$ has additional noise attributed to DIC. The DIC system has a minor limitation that causes it to lose accuracy when reading very close to the edge of a patterned area, hereafter referred to as the "edge effect." In DIC, strains are calculated by averaging measured displacement data from nearby facets. When nearby facets do not exist (e.g., at a plate edge), the accuracy of the measured strains is diminished. Therefore, the scatter of data at the edges of a plate, as can be seen near $y= \pm t / 2$ in Figure 6, should be ignored. In locations with peak strain at the edge of a patterned area, this results in lower peak strain measurements. It should be noted that 2D and 3D FE models agree closely with one another for the wider $203 \mathrm{~mm}$ (8 in.) plates, while some discrepancy can be observed toward the edges for the narrower $76.2 \mathrm{~mm}(3 \mathrm{in}$.) plates, especially for the $\theta=30^{\circ}$ bend angle. This is consistent with the findings for the circumferential strains on the tensile and compressive faces.

The close agreement (i.e., the distribution of strain showing similar patterns such as locations of peak strain being near plate edges, and similar magnitudes of peak strain) between the measured and the 3D FE model results is visually evident in the full-field circumferential strains shown on both faces of a representative $\theta=30^{\circ}$ sample (Figure 7 ), as 
well as through the sample thickness (Figure 8). The peak strain on the sides of the plates is predicted to be at the edges, and thus this "edge effect" results in lower measured peak strains as shown in Figure 8.

From Figure 5 it can be observed (in both the measured and numerical data) that the magnitude of peak strain is larger on the tensile face compared to the compressive face, regardless of the plate width or bend angle [aside from the $76.2 \mathrm{~mm}$ (3 in.) wide plate with a bend angle of $\theta=30^{\circ}$ as discussed earlier]. This indicates a neutral axis shift. This neutral axis shift is also evident in the through-thickness circumferential strains (Figure 6 and 8). This is consistent with the literature which indicates a shift in the neutral axis toward the compressive face by around 5\% [74]. Figure 5 compares the measured and numerical results with analytical predications when the neutral axis has not been shifted ("0\% NA Shift," Equation 3) and when the neutral axis has been shifted by 5\% ("5\% NA Shift," Equation 4). The peak measured and numerically predicted circumferential strains for the $\theta=20^{\circ}$ and the $\theta=30^{\circ}$ bend angles fall roughly between these two analytical predictions. However, these equations overpredict the measured and numerical behaviors for the $\theta=10^{\circ}$ bent plates by approximately 40\%. This discrepancy occurs because the analytical predictions assume no dependence on bend angle (to be discussed further in Section 7.2.3). Similar trends between the analytical, numerical, and measured values can be observed through the thickness on the plate sides (Figure 6). The measured neutral axis shifts in this research were found to range between $2.79 \%$ and $5.12 \%$, with a wide spread of data (a difference of roughly $1.5 \%$ shift) even for the same configuration (i.e., combination of bend angle and plate width). Given this wide spread of measured data, the assumption of a $5 \%$ neutral axis shift is reasonable for the simplified analytical predictions and this research is not able to provide a more refined value.

As can be visually observed in Figure 7 and shown in Figure 9, the 3D FE models are able to closely predict the distribution of circumferential strains along the plate width (i.e., similar patterns in strain distribution and peak magnitude in Figure 7 and $6.27 \%$ average absolute error across all FE data contained in Figure 9). Consistent with the observations made for the circumferential distribution of these circumferential strains (Figure 5), the only exception is that the 3D FE model overpredicts the compressive circumferential strains for the $76.2 \mathrm{~mm}$ (3 in.) wide plate with a bend angle of $\theta=30^{\circ}$ as discussed earlier. The measured strains at the plate edges (approaching $z= \pm w / 2$ ) also include increased noise due to the "edge effect" as discussed earlier. Overall, the circumferential strains are relatively constant across the plate width $(z)$ along the transverse midline $(x=0 \mathrm{~mm})$, except near the edges $(z= \pm w / 2)$ where an increase is observed. In the 3D FE models, this increase was between $8 \%$ to $30 \%$ [corresponding to a strain increase of $0.00706 \mathrm{~mm} / \mathrm{mm}$ to $0.0169 \mathrm{~mm} / \mathrm{mm}(0.00706 \mathrm{in}$./in. to 0.0169 in./in.) respectively]. Note that these values are provided for the FE models instead of measured data because of the additional noise in the measured data at the plate edges. This strain increase is most significant with the $\theta=30^{\circ}, 203 \mathrm{~mm}$ ( 8 in.) wide plates, whereas decreasing either the bend angle or the plate width cause this effect to become less significant. This is consistent with observations made by Sangdahl et al. (1948) [19] who found that the relative magnitude of the circumferential strain increase becomes larger as the plate width increases. However, Sangdahl et al. (1948) [19] found strain increases to never exceed $10 \%$ of the strain at $z=0 \mathrm{~mm}$, while this study demonstrated much larger relative shifts (up to 30\%). This difference is due to the materials investigated in each study, as 
Sangdahl et al. (1948) [19] focused on the behavior of aluminum alloy plates. This effect is discussed in further detail in Section 7.2.1 and 7.2.4.

\subsubsection{Transverse Strain Distribution}

Figure 10 compares the measured and numerical transverse strains $\left(\epsilon_{z}\right)$ as a function of the distance $(z)$ along the width at the transverse midline $(x=0 \mathrm{~mm})$ on the tensile and compressive faces of the plate. Overall, the 3D FE model is able to closely predict the measured behavior regardless of bend angle or plate width (i.e., plot shows near overlap of FE and measured data; percent errors not included as values are close to zero). The close agreement (i.e., similar patterns in strain distribution) between the measured and 3D FE model results is visually evident in the full-field transverse strains shown on both faces of representative $\theta=30^{\circ}$ samples (Figure 11). It can be seen that the FE results tend to show higher peak strains than the measured DIC results. This can be attributed to the "edge effect" as the peak values of transverse strain are predicted at the edges of the plate.

Like the circumferential strain, the transverse strain $\left(\epsilon_{z}\right)$ increases in magnitude from effectively zero at the longitudinal midline $(z=0 \mathrm{~mm})$ to a larger value at the edges $(z= \pm$ $\mathrm{w} / 2$ ) as shown in Figure 10. The peak transverse strain at the edges, taken from 3D FE results, is found to vary from $0.0206 \mathrm{~mm} / \mathrm{mm}$ to $0.0379 \mathrm{~mm} / \mathrm{mm}(0.0206 \mathrm{in}$./in. to 0.0379 in./in.) depending on bend angle (with greater strains corresponding to larger bend angle). This is expected since there is less transverse restraint at the edges, causing Poisson's effect to induce a strain rather than a stress in the transverse $(z)$ direction. In other words, the system approaches a plane stress state as opposed to a plane strain state that occurs at the longitudinal midline as will be discussed further in the parametric study in Section 7.2 .1 and 7.2.4.

\subsubsection{Summary of Finite Element Model Validation}

Overall, the 3D FE models can be considered validated. While the 2D FE models are far less computationally expensive, they are not able to closely predict circumferential strains for narrow plates bent to larger angles. A parametric study was performed to extend the results and discussion further, including additional plate thicknesses $[6.35 \mathrm{~mm}$ (0.25 in.), $19.1 \mathrm{~mm}$ (0.75 in.)] and plate widths [12.7 mm (0.5 in.), $140 \mathrm{~mm}(5.5$ in.)]. Relevant results from this parametric study will be included in the following section to consider contact area, modeling recommendations, peak circumferential strain, and strain state $\left(\epsilon_{z} / \epsilon_{x}\right)$.

\subsection{Parametric Study}

\subsubsection{Contact Area}

Based on numerical FE predictions (including results from the validated numerical models and the extended parametric studies) for plates with thickness $t=12.7 \mathrm{~mm}$ (0.5 in.), it can be observed that the region of the plate in contact with the top die depends on the angle of the bend and the plate width (Figure 12). This figure shows contact pressures exceeding $34.5 \mathrm{MPa}(5 \mathrm{ksi})$, which was considered to be a lower bound pressure indicating contact.

First, it can be observed that the contact pressure shifts along the circumferential length $(x)$ with increasing bend angle. At $\theta=10^{\circ}$, contact pressure is along the transverse midline $(x=0 \mathrm{~mm})$ for plates at least $76.2 \mathrm{~mm}(3 \mathrm{in}$. $)$ wide. For the narrowest plates $[w=12.7 \mathrm{~mm}(0.5$ in.)] the $2 \mathrm{D}$ and $3 \mathrm{D} \mathrm{FE}$ models disagree on whether the plate is in contact at the transverse 
midline, as shown in Figure 12. This is due to the assumption in the 2D FE models of a plane strain state, which loses validity for the narrowest plates [e.g., $w=12.7 \mathrm{~mm}$ (0.5 in.)] because they are closer to a plane stress environment. The 3D models capture the strain state more accurately, and thus predict contact away from the transverse midline. For all plate widths, as the plates are pressed further to $\theta=20^{\circ}$ and $\theta=30^{\circ}$, the contact location moves along the circumferential length towards the bottom die support (Figure 12). This indicates that the press braking process is shifting from a three-point bending environment for small angles toward a four-point bending environment for larger angles. This is demonstrated numerically in Figure 13 and Figure 14 where the contact pressure and circumferential strains are shown as the top die is pressed.

The shift from three- to four-point bending can be attributed to the nonuniform curvature of the plate, as expected with press braking processes [19]. As the top die is pressed and the bend angle increases, increasing circumferential strains induce additional curvature of the plate. When the plate is pressed to high bend angles (above $10^{\circ}$ in this research) the curvature exceeds that of the top die, and a gap opens between the plate and the top die at the transverse midline [20], putting the system in four-point bending. Initially, when the plate is in three-point bending, the transverse midline of the plate experiences the highest moment and plastic deformation initiates along the transverse midline (Figure 13 and 14). Due to the yield plateau in the plate's stress strain relationship (Figure 3), the yielded regions of the plate have little post-yield stiffness until reaching strain hardening $(\epsilon \geq 0.02)$. Therefore, until strain hardening initiates, a plastic hinge locally develops around the transverse midline causing curvature to be concentrated along the transverse midline of the plate. Thus, the curvature of the plate exceeds the curvature of the top die, putting the plate into four-point bending (Figure 13 and 14). After strain hardening is reached and the transverse midline of the plate increases in stiffness, the plastic hinge begins to widen as shown in Figures 13 and Figure 14). Four-point bending creates a plateau in the moment at the center of the plate, rather than a single peak location, and alters the distribution of circumferential strains by creating a "shoulder" around the peak strain value in the center. This can be observed for the tensile face of the $\theta=20^{\circ}$ and $\theta=30^{\circ}$ plates in Figure 5 . It is not seen in the tensile face of the $\theta=10^{\circ}$ plates as these plates are still in three-point bending.

Secondly, it can be observed that the edges (near $z= \pm w / 2$ ) of the compressive face are not in full contact with the top die (Figure 12). This can be attributed to the "softening" near the plate edges due to less transverse restraint, resulting in a downward curvature of the plate at the edges as measured in the plate samples (Figure 15). This can also be observed numerically in Figure 13 and Figure 14 where the free edge of the plate $(z= \pm w / 2$, red line) is shown to have more curvature than the longitudinal midline ( $z=0 \mathrm{~mm}$, yellow line). More specifically, at the edges where there is less transverse restraint, Poisson's effect induces a strain, rather than a stress in the transverse $(z)$ direction. This was observed in the increase in transverse strains near $z= \pm w / 2$ in Figure 10 and 11. Near the longitudinal midline, the plate approaches a plane strain state, and near the edges the plate approaches a plane stress state due to the lack of lateral restraint. It follows that at the onset of yielding, the circumferential stress at the edges of the plate will be larger (since the transverse stress is zero) than that at longitudinal midline (for which the transverse stress is nonzero). This relationship in circumferential stresses is reflected in the circumferential strains $\left(\epsilon_{x}\right)$, which are larger at the plate edges than at the longitudinal midline. This was observed in Figure 7 
and 9. As the edges experience more plastic deformation, the larger circumferential strains result in increased curvature, pulling the plate downward, away from the die relative to the longitudinal midline of the plate. This "softening" effect was observed in the samples, where the edges were measured to curve downward away from the top die for both the $76.2 \mathrm{~mm}$ (3 in.) and $203 \mathrm{~mm}$ (8 in.) plates (Figure 15).

As noted earlier, the 3D FE model overpredicted the compressive circumferential strains near $x=0 \mathrm{~mm}$ and the 2D FE model underpredicted the tensile circumferential strains near $x=0 \mathrm{~mm}$ compared to the measured data (Figure 5). This was attributed to (1) the assumption of frictionless interaction between the plate and the dies, and (2) the degree of transverse restraint at the longitudinal midline which affects the location and magnitude of the contact pressure and therefore the friction. Figure 12 shows that the contact pressure increases with bend angle and that therefore friction would play the most significant role with larger bend angles. The impact of the degree of transverse restraint on location and magnitude of peak contact pressure can also be observed from the 3D FE numerical predictions in Figure 12. The wider $203 \mathrm{~mm}$ (8 in.) plates have a greater degree of transverse restraint and larger transverse length away from the longitudinal midline $(z=0 \mathrm{~mm})$ over which there is constant contact compared to the $76.2 \mathrm{~mm}$ (3 in.) plates (related to the "softening" discussed above). Further, the location of the peak contact pressure is further away from the longitudinal midline $(z=0 \mathrm{~mm})$, and therefore the location for which circumferential strains are compared in Figure 5, for the wider $203 \mathrm{~mm}$ (8 in.) plates. The 2D FE models are not able to capture this relationship between transverse restraint and contact pressure (as shown in Figure 12), hence the difference between the $2 \mathrm{D}$ and $3 \mathrm{D}$ FE predictions. The limit for which $2 \mathrm{D} \mathrm{FE}$ modeling is able to sufficiently capture peak circumferential strains will be explored further in the next section based on data from the parametric study.

\subsubsection{Modeling Recommendations}

Depending on the width to thickness ratio $(w / t)$ of the plate and the bend angle $(\theta)$, a 2D FE model can be sufficient to capture the circumferential strains induced during the press braking process. Note that the $w / t$ ratios are based on nominal dimensions and do not take into account changes in thickness or width that occur during bending. It was found that with large $w / t$ ratios $\left(w / t>5\right.$ for $\theta=10^{\circ}, w / t>10$ for $\theta=20^{\circ}$ and $w / t>15$ for $\left.\theta=30^{\circ}\right)$, the 2D FE models agree more closely with the 3D FE models as shown in Figure 16. This is because plates with large $w / t$ ratios approach a plane strain state. With larger bend angles, friction engages more and therefore the degree of transverse restraint (which affects the location and magnitude of the contact pressure and therefore the friction) becomes more important. As a result, larger $w / t$ ratios are required for $2 \mathrm{D} \mathrm{FE}$ models to be sufficient at larger bend angles. Minimum $w / t$ ratios limiting when a $2 \mathrm{D}$ model is sufficient to capture circumferential strains (discussed above, shown by the vertical dashed line in Figure 16) can be used as recommendations in a design environment.

\subsubsection{Peak Circumferential Strain}

As shown in Figure 5, the measured and numerical peak circumferential strain is nearly the same for the $\theta=20^{\circ}$ and $\theta=30^{\circ} 12.7 \mathrm{~mm}$ ( $0.5 \mathrm{in}$.) thick bent plates. However, the peak is significantly smaller for the $\theta=10^{\circ}$ bent plates. As a result (and as discussed earlier in 
section 7.1.1), the analytic predictions for peak strain more closely match the $\theta=20^{\circ}$ and $\theta=30^{\circ}$ measured and numerical data.

Figure 17 considers the dependence of the peak circumferential strain on bend angle. It can be observed that for the thinnest plates [i.e., $t=6.35 \mathrm{~mm}(0.25 \mathrm{in}$.), corresponding to a bend radius of 16t], there is little dependence of the peak circumferential strain on the bend angle. Indeed, the analytical predictions are able to closely match the numerical predictions. As the plate thickness increases, the dependence of the peak circumferential strain on bend angle is apparent, with this dependence asymptoting with larger bend angles. This dependence of the peak circumferential strain on bend angle is consistent with the findings of Sangdahl et al. (1948) [19]. It can also be observed that the peak circumferential strain is largely independent of the plate width.

\subsubsection{Strain State}

The strain state is further investigated here as Figure 18 demonstrates (using 3D FE numerical predictions) that the strain state $\left(\epsilon_{z} / \epsilon_{x}\right)$ approaches plane strain $\left(\epsilon_{z} / \epsilon_{x}=0\right)$ toward the longitudinal midline and approaches plane stress $\left(\epsilon_{z} / \epsilon_{x}=-0.5\right.$ [73]) toward the edges (Figure 18, where the horizontal axis represents the length from one edge).

The edge transition length, that is the length over which the strain state varies from maximum to minimum (from approximately 0 to -0.5 ), depends primarily on the thickness of the plate $(t)$ and the bend angle $(\theta)$. Thicker plates [e.g., $t=19.1 \mathrm{~mm}(0.75 \mathrm{in}$. $)$ ] were found to have longer edge transition lengths than thinner plates [e.g., $t=6.35 \mathrm{~mm}(0.25 \mathrm{in}$.)]. Larger bend angles $\left(\theta=30^{\circ}\right)$ also increased the edge transition length compared to smaller bend angles $\left(\theta=10^{\circ}\right)$, causing more of the plate to deviate from a plane strain environment for larger bend angles. This edge transition length is generally unaffected by the width of the plate. For narrower plates [e.g., $w=12.7 \mathrm{~mm}(0.5 \mathrm{in})$.$] , an approximately plane strain$ state is not achieved. The plates with large width to thickness ratios $(w / t)$ tend to have the largest regions in a plane strain environment, as shown in Figure 18.

The slope of the strain state at the edge is found to be similar for plates of different widths, as shown in Figure 18, where for a given thickness and bend angle the width did not affect the shape of the strain state at the edge. This is consistent with the findings of Sangdahl et al. (1948) [19]. The thickness is found to affect the slope of the strain state at the edge, where thicker plates [e.g., $t=19.1 \mathrm{~mm}(0.75 \mathrm{in}$.)] tended to have a smaller slope than thinner plates [e.g., $t=6.35 \mathrm{~mm}(0.25 \mathrm{in}$.)].

The above discussion is relevant for all plates except the narrowest [w=12.7 $\mathrm{mm}(0.5 \mathrm{in})$.$] .$ These narrow plates have a width to thickness ratio below 3, meaning that they exhibit beam type behavior as opposed to plate type behavior [76]. This changes the shape of their strain state as shown in Figure 18, where they are in a nearly plane stress environment. The thicker, narrow plates [e.g., $t=12.7 \mathrm{~mm}$ (0.5 in.) and $19.1 \mathrm{~mm}(0.75$ in.) with $w=12.7 \mathrm{~mm}$ (0.5 in.)] have strain states beyond -0.5 , the value for a plane stress environment [73]. This can be attributed to their low span to thickness ratios (9 and 6 respectively) which make their behavior shear dominant as opposed to bending dominant. Their shear dominant, beam type behavior leads to local effects causing the strain state to exceed -0.5 , as shown in Figure 18. 


\section{Simplified Method for Predicting Peak Strains in the Field}

Due to Poisson's effect, the faces of the plate change width during bending, with the compressive face widening and the tensile face narrowing (see $w_{C}$ and $w_{T}$, the measured width of the compressive and tensile faces after bending, respectively, in Table 1). This paper proposes that this behavior can be used to predict the peak circumferential strain induced during bending. This is useful as a quality control measure for contractors and fabricators in situations where the exact bend radius is unknown, or not clearly defined.

More specifically, the average transverse strain of the bent plate can be found by measuring the width of the plate on the compressive and tensile faces of the plate after bending. The average width is calculated from these measurements. The difference between the average width and the compressive and tensile face widths is then used to determine the measured average transverse strain. Note that this method assumes that the average transverse strain on both faces is the same. While they are slightly different due to the neutral axis shift, this assumption is a simplifying approximation as the neutral axes shifts are generally below $5 \%$. The measured average transverse strain can then be used to predict the peak circumferential strain by Poisson's ratio and a coefficient $(\lambda)$ developed in this paper and discussed below. More specifically, the predicted peak circumferential strain on the tensile $\left(\epsilon_{x t p}\right)$ and compressive $\left(\epsilon_{x c p}\right)$ faces are found by:

$$
\begin{aligned}
& \epsilon_{x t p}=\frac{\left(\frac{2 w_{T}}{w_{T}+w_{C}}-1\right) \lambda_{t}}{\nu_{P L}} \\
& \epsilon_{x c p}=\frac{\left(\frac{2 w_{C}}{w_{T}+w_{C}}-1\right) \lambda_{c}}{\nu_{P L}}
\end{aligned}
$$

where $\lambda_{t}$ is a coefficient for the tensile face, $\lambda_{c}$ is a coefficient for the compressive face, and $\nu_{P L}$ is Poisson's ratio for plastic deformation of steel $\left(\nu_{P L}=0.5\right)$.

The coefficient $\lambda$ is found through FE numerical predications for a given width and thickness plate. More specifically, $\lambda$ is the ratio of the average transverse strain $\left(\epsilon_{\text {zavg }}\right)$ and the peak transverse strain $\left(\epsilon_{z \max }\right.$, Figure 19): $\lambda=\epsilon_{z \max } / \epsilon_{z a v g}$. Here, the average transverse strain is found by numerically integrating using a Reimann sums approximation. The area is then divided by the width of the plate to determine the predicted average transverse strain:

$$
\epsilon_{z a v g}=\frac{\left(\int_{-w / 2}^{w / 2} \epsilon_{z} d z\right)}{w}
$$

This method was implemented for the 18 plates investigated in this research (Table 3). It can be observed that this method provides a reasonable prediction of the peak circumferential strain with a moderate level of precision for plates bent to $\theta=20^{\circ}$ and $\theta=30^{\circ}$ (i.e., the maximum error with respect to the measured DIC results is 17.9\%). Smaller bend angles $\left(\theta=10^{\circ}\right)$ were found to have larger errors (i.e., up to $51.7 \%$ error with respect to the measured DIC results), due to the smaller magnitude of measured displacements increasing the impact of measurement precision on the accuracy of the results. As a result, this technique is overly conservative for small bend angles $\left(\theta=10^{\circ}\right)$. However, over-conservatism for small bend angles is not a limitation since an accurate predictor for larger bend angles is of a 
greater priority as they lead to larger strains. A factor of safety could be included so that this method provides a conservative estimate of the peak strain.

With this method validated, $\lambda$ coefficients were found for each combination of width and thickness in the parametric study (Table 4). The $\lambda$ coefficients increase with increasing width to thickness ratio because wider plates have a larger proportion of their width in an approximately plane strain state, decreasing the average transverse strain while the peak stays constant (Figure 20). Note that $\lambda$ coefficients were not found for the $12.7 \mathrm{~mm}(0.5$ in.) because they did not follow the same trends in strain state as the rest of the data. This alters the distribution of their transverse strains, as discussed previously in Section 7.2.4, and reduces the applicability of this $\lambda$ calculation. With this table, a contractor or fabricator can calculate the predicted peak circumferential strain - a crucial measure of the impact on ductility and fracture toughness. Therefore this method provides a useful quality control method for situations where the bend radius is unknown or not clearly defined.

\section{Conclusions}

This research investigated the strains induced in 18 samples of $12.7 \mathrm{~mm}(0.5 \mathrm{in}$.$) thick A36$ steel plates during cold bending to $\theta=10^{\circ}, 20^{\circ}$, and $30^{\circ}$ using DIC. 2D and 3D FE numerical models were created and compared with full field strain maps measured with DIC. The 2D and 3D FE numerical models agree closely (i.e., an average absolute error across all data points less than or equal to $17.0 \%$ ) with the measured results. For the narrower $[76.2 \mathrm{~mm}$ (3 in.)] plates with a larger bend angle $\left(\theta=30^{\circ}\right)$, the $3 \mathrm{D}$ FE model overpredicted the peak compressive circumferential strains and the 2D FE model underpredicted the peak tensile strains. This can be attributed to (1) the assumption of frictionless interaction between the plate and the dies, and (2) the degree of transverse restraint at the longitudinal midline which affects the location and magnitude of the contact pressure and therefore the friction. Overall, however, the numerical models can be considered validated.

A parametric study, using the validated finite element models, was completed to consider additional widths $[w=12.7 \mathrm{~mm}(0.5 \mathrm{in}$.$) and w=140 \mathrm{~mm}(5.5 \mathrm{in})$.$] and thicknesses [t=6.35$ $\mathrm{mm}$ (.25 in.) and $t=19.1 \mathrm{~mm}$ (.75 in.)]. Based on the results of this study, the authors recommend using a 3D FE model when investigating cold bending of steel plates with width to thickness ratios less than 5, 10, and 15 for bend angles of $\theta=10^{\circ}, \theta=20^{\circ}$, and $\theta=30^{\circ}$ respectively. 2D FE models run significantly faster than 3D and are more suitable for a design environment. The peak circumferential strain was found to depend on bend angle. Simplified analytical equations were capable of predicting peak circumferential strains for larger bend angles, but were not able to do so for smaller bend angles. The dependence of the peak circumferential strain on bend angle is also a function of the plate thickness, with thinner plates showing little dependence of peak circumferential strain on bend angle. The strain state is shown to approach plane strain towards the longitudinal midline of each plate, and plane stress towards the edges of each plate, with the exception of the narrowest plate.

A method of predicting peak circumferential strain was proposed based on measurements of the plate after bending. This method is found to provide a reasonable prediction (i.e., less than or equal to $17.9 \%$ error) of the induced circumferential strain in plates bent to angles $\theta=20^{\circ}$ and $\theta=30^{\circ}$, and could be used as a quality control measure for cold bending. It is overly conservative for small bend angles $\left(\theta=10^{\circ}\right)$. This is not a limitation, though, 
because the strains in larger bend angles are of more concern than smaller bend angles due to the larger magnitude of strains involved. This is an important quantity to understand as it relates to the ductility and fracture toughness.

With the recent changes in bridge design code to allow cold bending of fracture critical and non-fracture critical plates, this investigation is intended to further advance understanding of residual strains in cold bent steel plates. Cold bending can provide significant fabrication and scheduling advantages. It has also enabled unique and innovative designs to be implemented, such as on the Memorial Bridge [13].

\section{Acknowledgements}

This material is based upon work supported by the National Science Foundation under Grant No. CMMI-1351272. The support of Program Managers Drs. Kishor Mehta and and Y. Grace Hsuan is gratefully acknowledged. The authors are grateful to the University of Notre Dame Equipment Restoration and Renewal Program which funded the purchase of the DIC equipment. The authors are also grateful to Builders Iron Works, Inc. (Mishawaka, IN) for fabricating and press braking the samples at a reduced cost as well as Alro Steel for providing the steel at a reduced cost. 
[1] Schafer, B.W., Pekoz, T.. Computational modeling of cold-formed steel: Characterizing geometric imperfections and residual stresses. Journal of Constructional Steel Research 1998;47(3):193-210.

[2] Moen, C.D., Igusa, T., Schafer, B.W.. Prediction of residual stresses and strains in cold-formed steel members. Thin-Walled Structures 2008;46(11):1274-1289.

[3] FHWA, . Steel Bridge Design Handbook: Bridge Steels and their Mechanical Properties. Washington, D.C.: U.S. Department of Transportation, Federal Highway Administration (FHWA); 2015.

[4] Chajes, A., Britvec, S.J., Winter, G.. Effects of cold-straining on structural sheet steels. Journal of the Structural Division, Proceedings of the American Society of Civil Engineers 1963;89(2):1-32.

[5] Karren, K.W.. Corner properties of cold-formed steel shapes. Journal of the Structural Division, Proceedings of the American Society of Civil Engineers 1967;93(1):401-432.

[6] Gergess, A.N., Sen, R.. Fabrication of unsymmetrical curved plate girders by cold bending. Journal of Constructional Steel Research 2005;61(10):1353-1372.

[7] FHWA, . Steel Bridge Design Handbook: Steel Bridge Fabrication. Washington, D.C.: U.S. Department of Transportation, Federal Highway Administration (FHWA); 2015.

[8] Keating, P.B., Christian, L.C.. Effects of bending and heat on the ductility and fracture toughness of flange plate. 2012. Technical Report No. FHWA/TX-10/0-4624-2.

[9] AASHTO/NSBA, . Steel Bridge Fabrication Guide Specifications. Washington, D.C.: American Association of State Highway and Transportation Officials (AASHTO) and National Steel Bridge Alliance (NSBA), 2nd Edition; 2008.

[10] AASHTO, . AASHTO LRFD Bridge Construction Specifications. Washington, D.C.: American Association of State Highway and Transportation Officials (AASHTO), 3rd Edition, with 2010, 2011, 2012, 2014, 2015 and 2016 Interim Revisions; 2010.

[11] AASHTO, . AASHTO LRFD Bridge Construction Specifications. Washington, D.C.: American Association of State Highway and Transportation Officials (AASHTO), 2012 Interim Revisions to 3rd Edition; 2012.

[12] TXDOT, . Preferred practices for steel bridge design, fabrication, and erection. 2015. Texas Deparment of Transportation (TXDOT), Texas Steel Quality Council.

[13] Cota, K., Zoli, T.P.. Bridge design: Truss with a twist. Roads \& Bridges $2012 ; 50(12): 22-24,26-27$.

[14] Gergess, A.N., Sen, R.. Cold curving symmetric unstiffened I-girders. Journal of Constructional Steel Research 2005;61(4):473-492.

[15] Gergess, A.N., Sen, R.. Cold curving steel bridge girders. Journal of the Transportation Research Board 2008;2081:165-175. 
[16] Gergess, A.N., Sen, R.. Cold bending HPS 485W steel bridge girders. Journal of Constructional Steel Research 2009;65(8-9):1549-1557.

[17] HNTB Corporation, Genesis Structures, Inc., Structural Engineering Associates, Iowa State University, . Strategic Highway Report S2-R04-RR-1 Innovative Bridge Designs for Rapid Renewal. Washington, D.C.: Transportation Research Board; 2014.

[18] Brown Jr., W.F., Jones, M.H.. Strain analysis by photogrid method. Iron Age 1946;158(11):50-55.

[19] Sangdahl Jr., G.S., Aul, E.L., Sachs, G.. An investigation of the stress and strain states occurring in bending rectangular bars. Proceedings of the Society of Experimental Stress Analysis 1948;6(1):1-18.

[20] Weng, C.C., White, R.N.. Cold-bending of thick high-strength steel plates. Journal of Structural Engineering 1990;116(1):40-54.

[21] Key, P.W., Hancock, G.J.. A theoretical investigation of the column behavior of cold-formed hollow sections. Thin-Walled Structures 1993;16:31-64.

[22] Davison, T.A., Birkemoe, P.C.. Column behavior of cold-formed hollow structural steel shapes. Canadian Journal of Civil Engineering 1983;10(1):125-141.

[23] Sherman, D.R.. Residual stress measurement in tubular members. Journal of the Structural Division, Proceedings of the American Society of Civil Engineers 1969;95(4):635647.

[24] Sloof, P.A., Schuster, R.M.. Yield strength increase of cold formed sections due to cold work of forming. Fifteenth International Specialty Conference on Cold-Formed Steel Structures: Recent Research and Developments in Cold-Formed Steel Design and Construction 2000;:517-535.

[25] Abdel-Rahman, N., Sivakumaran, K.S.. Material properties models for analysis of cold-formed steel members. Journal of Structural Engineering 1997;123(9):1135-1143.

[26] de M. Batista, E., Rodrigues, F.C.. Residual stress measurements on cold-formed profiles. Experimental Techniques 1992;16(5):25-29.

[27] Weng, C.C., Pekoz, T.. Residual stresses in cold-formed steel members. Journal of Structural Engineering 1990;116(6):1611-1625.

[28] Dat, D.T.. The strength of cold-formed steel columns. Ph.D. thesis; Cornell University; Ithaca, NY; 1980.

[29] Ingvarsson, L.. Cold-forming residual stresses, effect of buckling. Third International Specialty Conference on Cold-Formed Steel Structures 1975;:85-119.

[30] Popovic, D., Hancock, G.J., Rasmussen, K.J.R.. Axial compression tests of coldformed angles. Journal of Structural Engineering 1999;125(5):515-523. 
[31] Schmidt, T., Tyson, J., Galanulis, K.. Part I: Full-field dynamic displacement and strain measurement using advanced 3D image correlation photogrammetry. Experimental Techniques 2003;27(3):47-50.

[32] ASTM,. ASTM A6/A6M-14: Standard specification for general requirements for rolled structural steel bars, plates, shapes, and sheet piling. 2014. West Conshohocken, PA.

[33] ASTM, . ASTM A370-14: Standard test methods and definitions for mechanical testing of steel products. 2015. West Conshohocken, PA.

[34] ASTM, . ASTM E111-04 (reapproved 2010): Standard test method for young's modulus tangent modulus, and chord modulus. 2010. West Conshohocken, PA.

[35] ASTM, . ASTM E132-04 (reapproved 2010): Standard test method for poisson's ratio at room temperature. 2010. West Conshohocken, PA.

[36] ARAMIS, . ARAMIS Software Version 6.3.1. 2013. GOM, Braunschweig, Germany.

[37] Ferro, . CerMark laser marking materials. 2016. http : //www.ferro.com/Our + Products/ColorsGlass/FunctionalIndustrial/CerMark/ (January 26, 2016).

[38] Schmidt, T., Tyson, J., Galanulis, K.. Part II: Full-field dynamic displacement and strain measurement using advanced 3D image correlation photogrammetry. Experimental Techniques 2003;27(4):22-26.

[39] Nelson D. V. Makino, A., Schmidt, T.. Residual stress determination using hole drilling and 3D image correlation. Experimental Mechanics 2006;46(1):31-38.

[40] Pan, B., Qian, K., Xie, H., Asundi, A.. Two-dimensional digital image correlation for in-plane displacement and strain measurement: A review. Measurement and Science Technology 2009;20(6):062001.

[41] Orteu, J.J.. 3-D computer vision in experimental mechanics. Optics and Lasers in Engineering 2009;47(3-4):282-291.

[42] McGinnis, M.J., Smith, B.J., Holloman, M., Lisk, M., O'Donnell, A., Kurama, Y.C.. 3-D digital image correlation - an underused asset for structural testing. Proceedings of the American Society for Civil Engineers Structures Congress 2012;:1958-1969.

[43] McCormick, N., Lord, J.. Digital image correlation for structural measurements. Proceedings of the Institution of Civil Engineers - Civil Engineering 2012;165(4):185190.

[44] Smith, B.J., Kurama, Y.C., McGinnis, M.J.. Design and measured behavior of a hybrid precast concrete wall specimen for seismic regions. Journal of Structural Engineering 2011;137(10):1052-1062.

[45] Mueller, K.A., Kurama, Y.C., McGinnis, M.J.. Out-of-plane behavior of two reinforced concrete bearing walls under fire: A full-scale experimental investigation. ACI Structural Journal 2014;111(5):1101-1110. 
[46] Heerema, P., Ashour, A., Shedid, M., El-Dakhakhni, W.. System-level displacement- and performance-based seismic design parameter quantifications for an asymmetrical reinforced concrete masonry building. Journal of Structural Engineering 2015;141(11):04015032.

[47] Linton, D., Gupta, R., Cox, D., van de Lindt, J.. Load distribution in light-frame wood buildings under experimentally simulated tsunami loads. Journal of Performance of Constructed Facilities 2015;29(1):04014030.

[48] Yoneyama, S., Kitagawa, A., Iwata, S., Tani, K., Kikuta, H.. Bridge deflection measurement using digital image correlation. Experimental Techniques 2007;31(1):3440.

[49] Chiang, C.H., Shih, M.H., Chen, W., Yu, C.P.. Displacement measurements of highway bridges using digital image correlation methods. Proceedings of the International Society for Optics and Photonics - The International Society for Optical Engineering 2011;8321:83211.

[50] Peddle, J., Goudreau, A., Carlson, E., Santini-Bell, E.. Bridge displacement measurement through digital image correlation. Bridge Structures 2011;7(4):165-173.

[51] Nonis, C., Niezrecki, C., Yu, T.Y., Ahmed, S., Su, C.F., Schmidt, T.. Structural health monitoring of bridges using digital image correlation. Proceedings of the International Society for Optics and Photonics - The International Society for Optical Engineering 2013;8695:869507.

[52] Busca, G., Cigada, A., Mazzoleni, P., Zappa, E.. Vibration monitoring of multiple bridge points by means of a unique vision-based measuring system. Experimental Mechanics 2014;54(2):255-271.

[53] Winkler, J., Hendy, C.R., Waterfall, P.. Improved structural health monitoring strategies for better management of civil infrastructure systems. Multi-Span Large Bridges - Proceedings of the International Conference on Multi-Span Bridges 2015;:855862.

[54] Jiang, C., Wu, Y.F., Wu, G.. Plastic hinge length of FRP-confined square RC columns. Journal of Composites for Construction 2014;18(4):04014003.

[55] Lord, J.D., Penn, D., Whitehead, P.. The application of digital image correlation for measuring residual stress by incremental hole drilling. Applied Mechanics and Materials 2008;13-14:65-73.

[56] ASTM, . ASTM E837-13a: Standard test method for determining residual stresses by the hole-drilling strain-gage method. 2013. West Conshohocken, PA.

[57] Gao, J., Shang, H.. Deformation-pattern-based digital image correlation method and its application to residual stress measurement. Applied Optics 2009;48(7):1371-1381. 
[58] Baldi, A.. Residual stress measurement using hole drilling and integrated digital image correlation techniques. Experimental Mechanics 2014;54(3):379-391.

[59] Baldi, A.. Residual stress analysis of orthotropic materials using integrated digital image correlation. Experimental Mechanics 2014;54(7):1279-92.

[60] Schajer, G.S.. Advances in hole-drilling residual stress measurements. Experimental Mechanics 2010;50(2):159-168.

[61] McGinnis, M.J., Pessiki, S., Turker, H.. Application of three-dimensional digital image correlation to the core-drilling method. Experimental Mechanics 2005;45(4):359-367.

[62] Hu, Z., Xie, H., Lu, J., Zhu, J., Wang, H.. Residual stresses measurement by using ring-core method and 3D digital image correlation technique. Measurement Science \& Technology 2013;24(8):085604.

[63] Schafer, B.W., Li, Z., Moen, C.D.. Computational modeling of cold-formed steel. Thin-Walled Structures 2010;48(10-11):752-762.

[64] Li, K.P., Cescotto, S.. An 8-node brick element with mixed formulations for large deformation analysis. Computational Methods in Applied Mechanics and Engineering 1997;141(1-2):157-204.

[65] Rossi, B., Degee, H., Boman, R.. Numerical simulation of the roll forming of thinwalled sections and evaluation of corner strength enhancement. Finite Elements in Analysis and Design 2013;72:13-20.

[66] Rossi, B., Afshan, S., Gardner, L.. Strength enhancements in cold-formed structural sections - part two: predictive models. Journal of Constructional Steel Research 2013;83:189-196.

[67] Quach, W.M., Teng, J.G., Chung, K.F.. Finite element predictions of residual stresses in press-braked thin-walled steel sections. Engineering Structures 2006;28(11):16091619 .

[68] Quach, W.M., Teng, J.G., Chung, K.F.. Residual stresses in press-braked stainless steel sections, II: press-braking operations. Journal of Constructional Steel Research 2009;65(8-9):1816-1826.

[69] Spoorenberg, R.C., Snijder, H.H., Hoenderkamp, J.C.D.. Finite element simulations of residual stresses in roller bent wide flange sections. Journal of Constructional Steel Research 2011;67(1):39-50.

[70] Skubisz, P., Ruminski, M., Lisiecki, L.. Estimation of strain-hardness correlation in cold-forged austenitic stainless steel. Key Engineering Materials 2014;622-623:179-185.

[71] Muller, M., Barrans, S.M., Blunt, L.. Predicting plastic deformation and work hardening during v-band formation. Journal of Materials Processing Technology 2011;211(4):627-636. 
[72] ABAQUS, . ABAQUS/Standard Analysis User's Manual Version 6.13. 2013. Dassault Systemes, Waltham, MA.

[73] Kervick, R.J., Springborn, R.K.. Cold Bending and Forming Tube and Other Sections. Dearborn, MI: American Society of Tool and Manufacturing Enigneers; 1966.

[74] Cook, N.H.. Manufacturing Analysis. Reading, MA: Addison-Wesley Co.; 1966.

[75] Johnson, W., Mellor, P.B.. Engineering Plasticity. New York, NY: Van Nostrand Reinhold; 1980.

[76] Timoshenko, S.P., Woinowsky-Krieger, S.. Theory of Plates and Shells. New York: McGraw-Hill; 1959. 


\begin{tabular}{|c|c|c|c|c|c|c|}
\hline Sample & $l(\mathrm{~mm})$ & $\theta(\mathrm{deg})$ & $w(\mathrm{~mm})$ & $w_{C}(\mathrm{~mm})$ & $w_{T}(\mathrm{~mm})$ & $t(\mathrm{~mm})$ \\
\hline 1 & 432.9 & 10.21 & 76.20 & 77.15 & 75.84 & 12.35 \\
2 & 433.5 & 10.19 & 76.28 & 77.14 & 75.76 & 12.46 \\
3 & 431.4 & 10.19 & 76.20 & 77.52 & 75.87 & 12.37 \\
4 & 433.9 & 9.174 & 201.0 & 201.5 & 200.5 & 12.42 \\
5 & 432.7 & 9.193 & 201.3 & 201.6 & 200.3 & 12.33 \\
6 & 434.0 & 9.365 & 201.3 & 201.7 & 200.6 & 12.43 \\
7 & 484.2 & 19.61 & 76.75 & 77.90 & 76.21 & 12.38 \\
8 & 483.4 & 19.63 & 76.37 & 77.69 & 76.02 & 12.37 \\
9 & 483.3 & 19.33 & 76.20 & 77.04 & 75.49 & 12.32 \\
10 & 482.7 & 18.85 & 200.8 & 201.6 & 200.0 & 12.43 \\
11 & 483.9 & 18.76 & 200.8 & 201.2 & 199.7 & 12.41 \\
12 & 483.4 & 18.84 & 201.0 & 201.3 & 200.0 & 12.43 \\
13 & 530.4 & 29.61 & 75.44 & 76.68 & 74.69 & 12.33 \\
14 & 533.2 & 29.63 & 76.37 & 77.52 & 75.62 & 12.40 \\
15 & 530.7 & 29.94 & 75.44 & 77.08 & 74.88 & 12.42 \\
16 & 531.9 & 28.98 & 201.3 & 201.3 & 199.8 & 12.45 \\
17 & 533.9 & 28.82 & 201.1 & 201.5 & 199.8 & 12.40 \\
18 & 531.5 & 29.01 & 201.0 & 201.4 & 199.5 & 12.46 \\
\hline
\end{tabular}

Table 1: Samples tested, including dimensions (Figure 2). $l=$ length prior to bending, $\theta=$ bend angle, $w=$ width prior to bending, $w_{C}=$ width of compressive face after bending, $w_{T}=$ width of tensile face after bending, $t=$ thickness prior to bending. Length and width measurements were made using a ruler with \pm 394 micron (0.01 in.) accuracy. Thickness measurements were made using a micrometer with \pm 2.54 micron (0.0001 in.) accuracy. 


\begin{tabular}{|l|c|c|c|c|}
\hline Property & $\begin{array}{c}E \\
(\mathrm{GPa})\end{array}$ & $\begin{array}{c}F_{y} \\
(\mathrm{MPa})\end{array}$ & $\begin{array}{c}F_{u} \\
(\mathrm{MPa})\end{array}$ & $\nu$ \\
\hline \multicolumn{5}{|l|}{ Bar 1 (4 samples) } \\
\hline Mean & 201 & 388 & 522 & 0.280 \\
Std. Dev. & 3.73 & 6.41 & 2.76 & $8.52 \mathrm{E}-4$ \\
COV (\%) & 1.85 & 1.65 & 0.529 & 0.305 \\
\hline Bar 2 (4 samples) \\
\hline Mean & 206 & 391 & 522 & 0.280 \\
Std. Dev. & 4.30 & 6.11 & 2.19 & $1.72 \mathrm{E}-3$ \\
COV (\%) & 2.09 & 1.56 & 0.419 & 0.616 \\
\hline All Samples \\
\hline Mean & 204 & 390 & 522 & 0.280 \\
Std. Dev. & 4.38 & 6.11 & 2.30 & $1.27 \mathrm{E}-3$ \\
COV (\%) & 2.15 & 1.57 & 0.442 & 0.453 \\
\hline
\end{tabular}

Table 2: Measured material properties of steel plates obtained through ASTM testing [32-35]. E=elastic modulus, $F_{y}=$ yield strength, $F_{u}=$ ultimate strength, $\nu=$ Poisson's ratio, Std. Dev.=standard deviation, $\mathrm{COV}=$ coefficient of variation. 


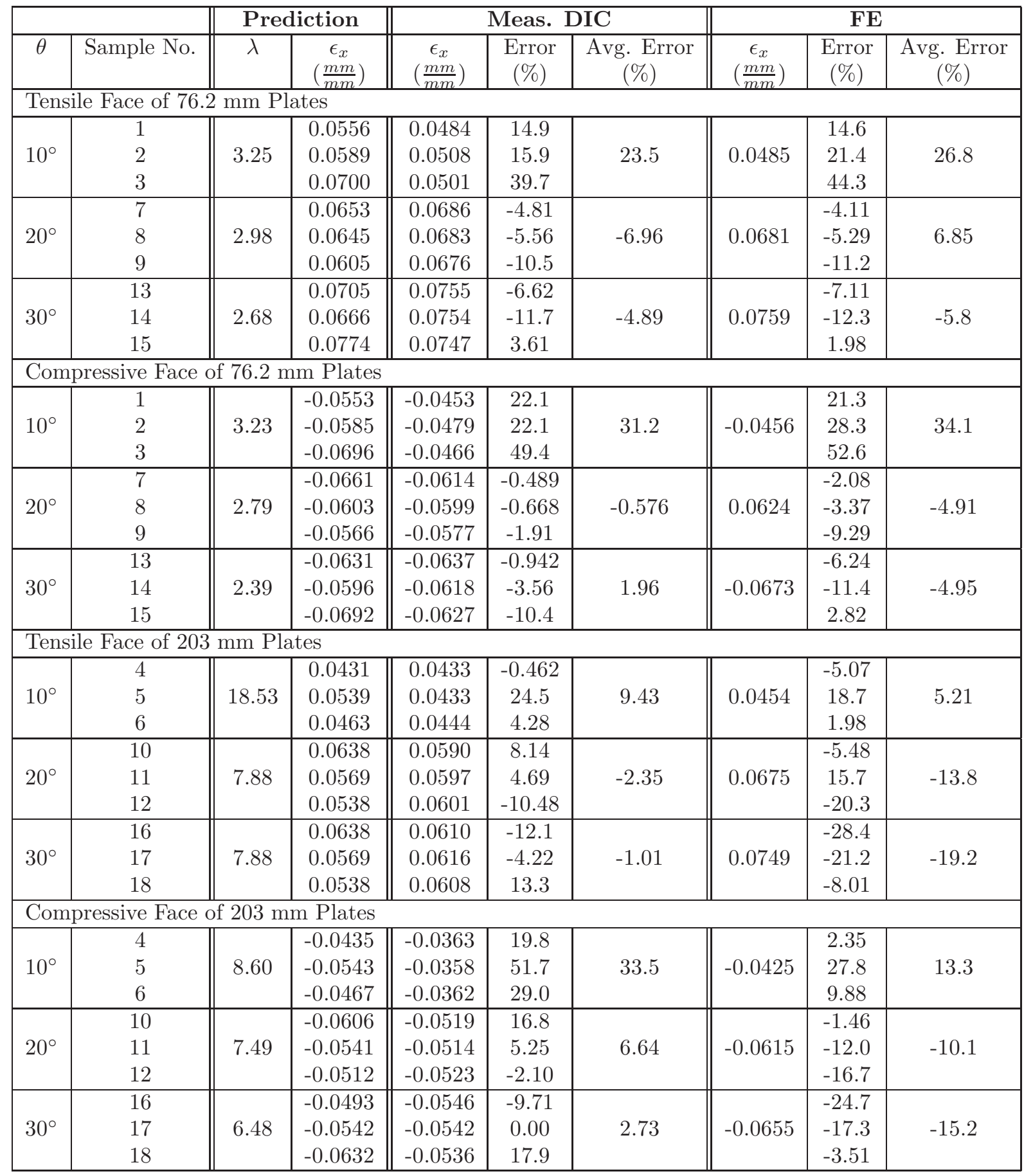

Table 3: Results of proposed method for predicting peak circumferential strain $\left(\epsilon_{x}\right)$ based on measurements of plate width after bending. 


\begin{tabular}{|c|c||c|c|c||c|c|c|}
\hline \multicolumn{2}{|c||}{} & \multicolumn{3}{c||}{ Tensile Face $\left(\lambda_{t}\right)$} & \multicolumn{2}{c|}{ Compressive Face $\left(\lambda_{c}\right)$} \\
\hline & Width $(\mathrm{mm})$ & $\theta=10^{\circ}$ & $\theta=20^{\circ}$ & $\theta=30^{\circ}$ & $\theta=10^{\circ}$ & $\theta=20^{\circ}$ & $\theta=30^{\circ}$ \\
\hline \multirow{3}{*}{$\mathrm{t}=6.35 \mathrm{~mm}$} & 76.2 & 4.87 & 3.94 & 3.50 & 4.92 & 3.69 & 3.04 \\
& 140 & 8.67 & 7.03 & 6.19 & 8.95 & 6.87 & 5.97 \\
& 203 & 12.8 & 10.3 & 8.99 & 13.5 & 10.3 & 8.97 \\
\hline \multirow{3}{*}{$\mathrm{t}=12.7 \mathrm{~mm}$} & 76.2 & 3.49 & 3.18 & 2.84 & 3.46 & 2.95 & 2.52 \\
& 140 & 6.28 & 5.64 & 4.97 & 6.25 & 5.39 & 4.84 \\
& 203 & 9.13 & 8.39 & 7.47 & 9.20 & 7.95 & 6.82 \\
\hline \multirow{3}{*}{$\mathrm{t}=19.1 \mathrm{~mm}$} & 76.2 & 2.62 & 2.52 & 2.36 & 2.62 & 2.37 & 2.09 \\
& 140 & 4.75 & 4.59 & 4.30 & 4.77 & 4.35 & 3.82 \\
& 203 & 6.87 & 6.67 & 6.27 & 6.97 & 6.37 & 5.62 \\
\hline
\end{tabular}

Table 4: Coefficients $(\lambda)$ for predicting peak circumferential strain $\left(\epsilon_{x}\right)$. 


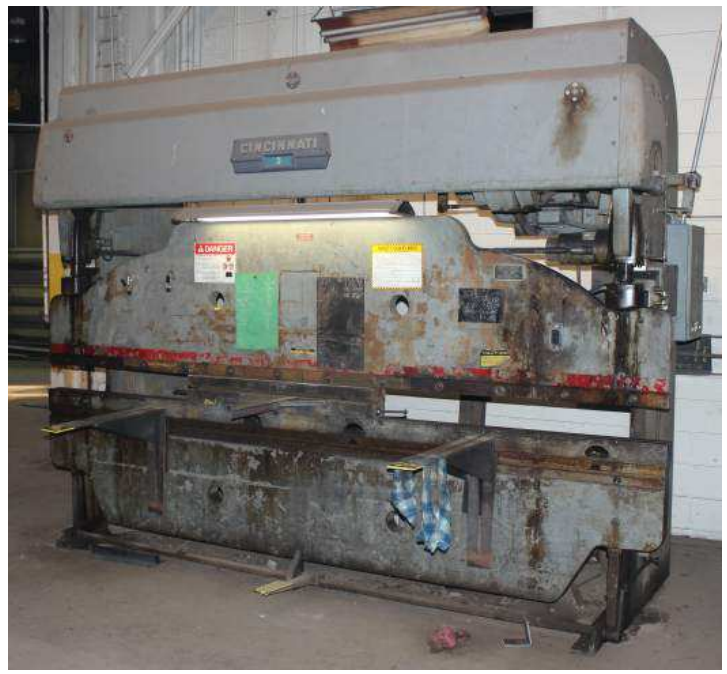

(A)

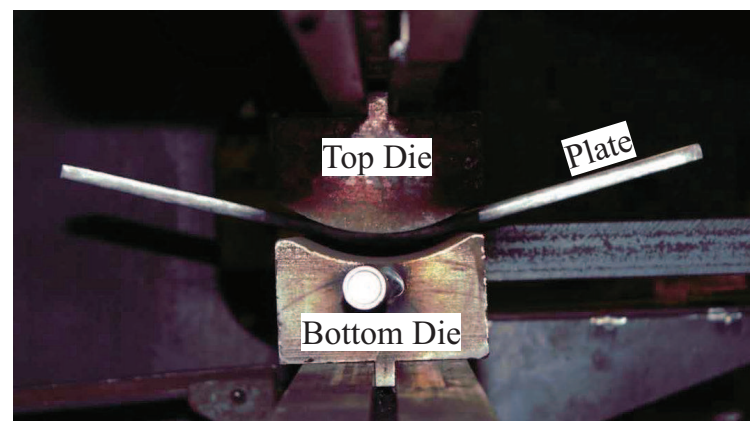

(B)

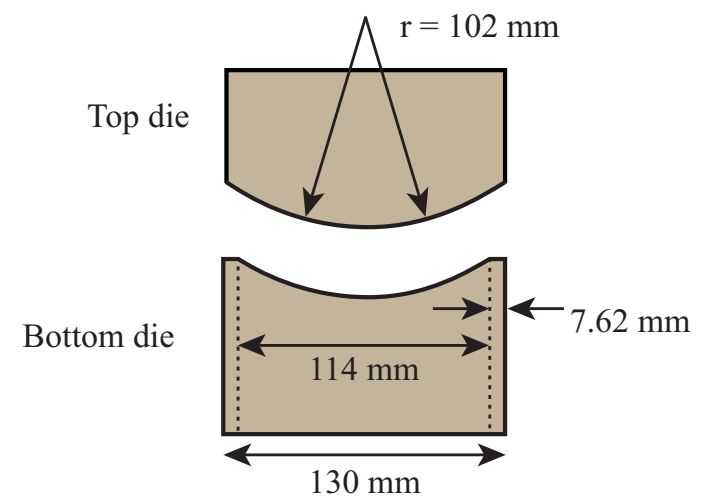

(C)

Figure 1: Press brake used for bending, including (A) photograph of press brake, (B) photograph of press brake as specimen is being bent, and (C) rendering of top and bottom dies, including dimensions. 


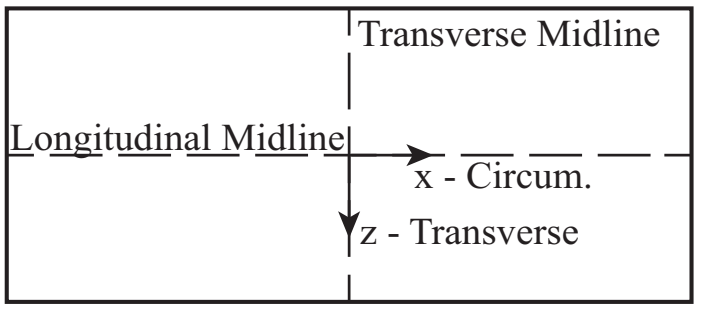

(A)

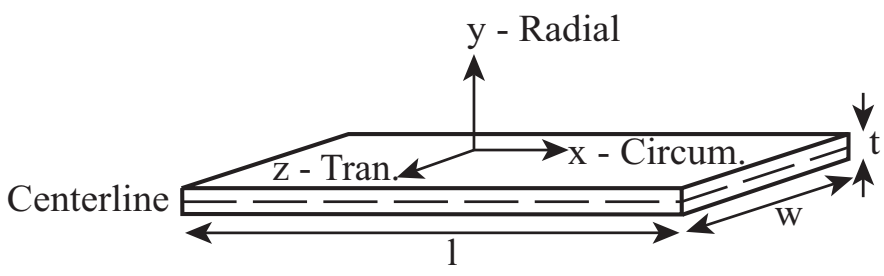

(B)

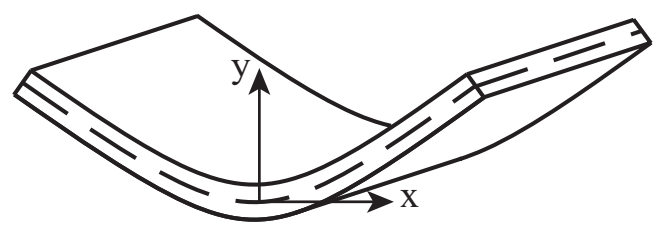

(C)

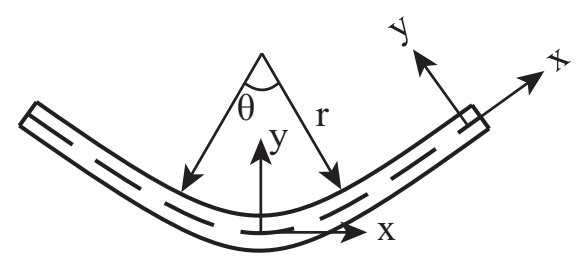

(D)

Figure 2: Coordinate system and definition of geometric parameters, shown for (A) plan view of plate before bending, (B) isometric view of plate before bending, (C) isometric view of plate after bending, and (D) elevation of plate after bending. Circumferential (Circum.), Radial, and Transverse (Trans.) axes are indicated. The figures shown indicate shapes from three-point bending (consistent with small bend angles). Note that shapes would be different for four-point bending (consistent with larger bend angles). 


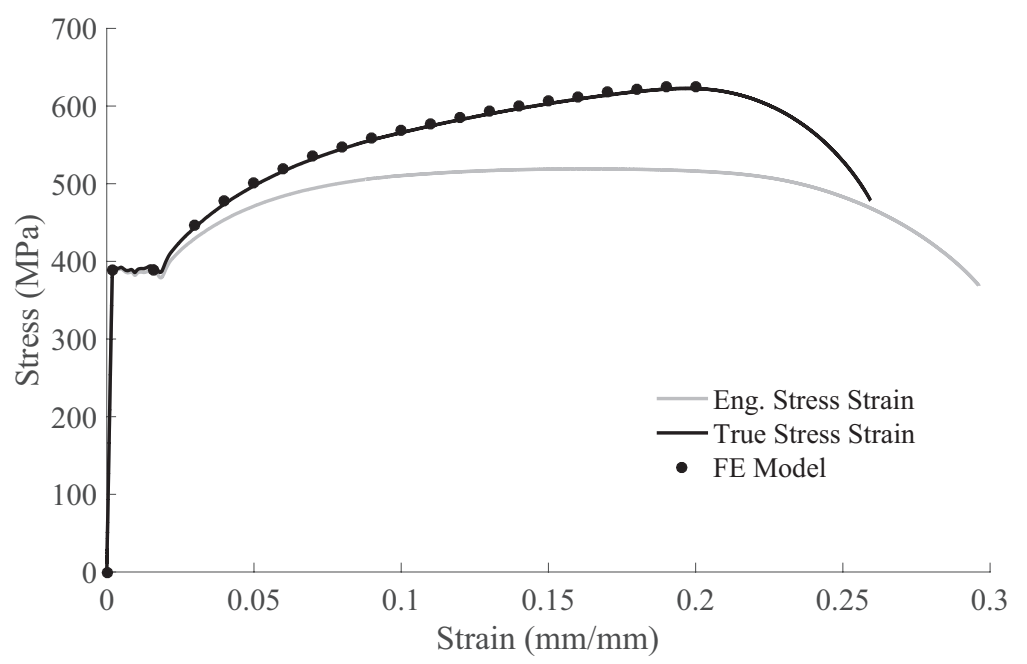

Figure 3: Engineering (Eng.) and true stress strain relationship for a representative material sample. Black circles indicate data used in the FE models. 


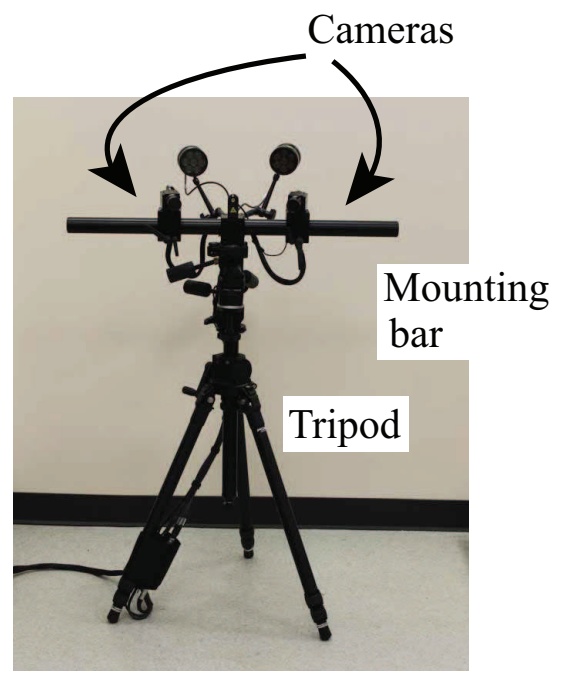

Figure 4: Photograph of DIC cameras on a rigid mounting bar supported by a tripod. 
Tensile Face
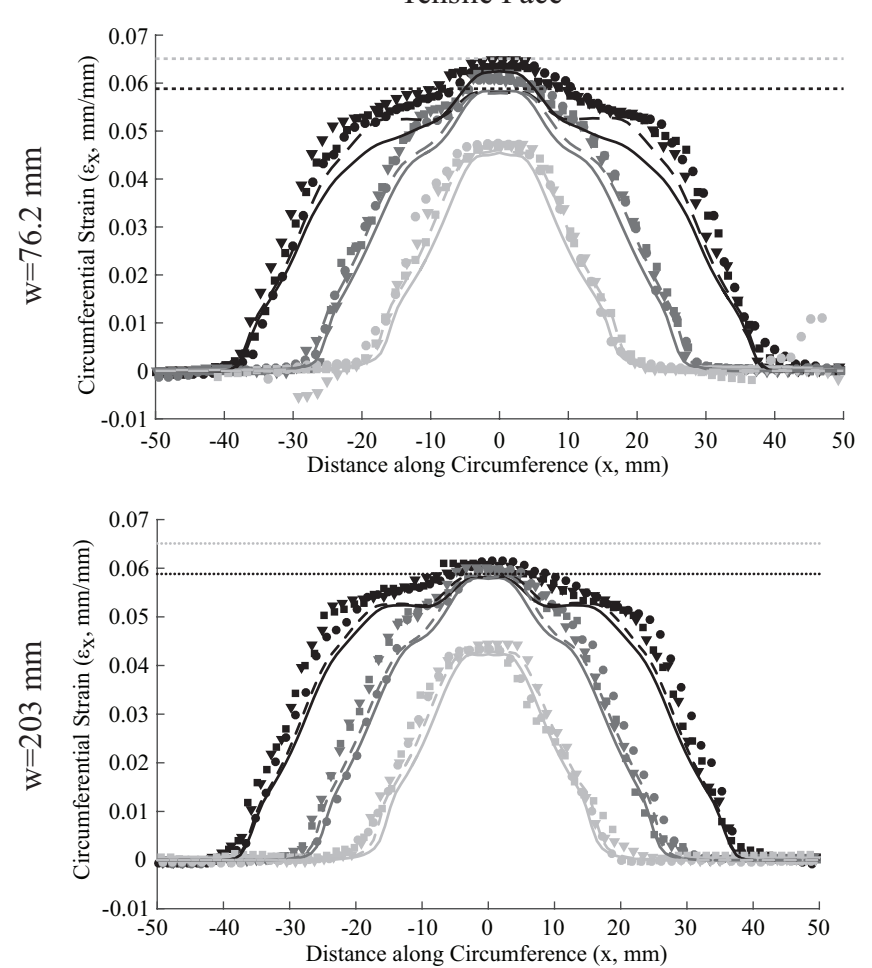

Compressive Face
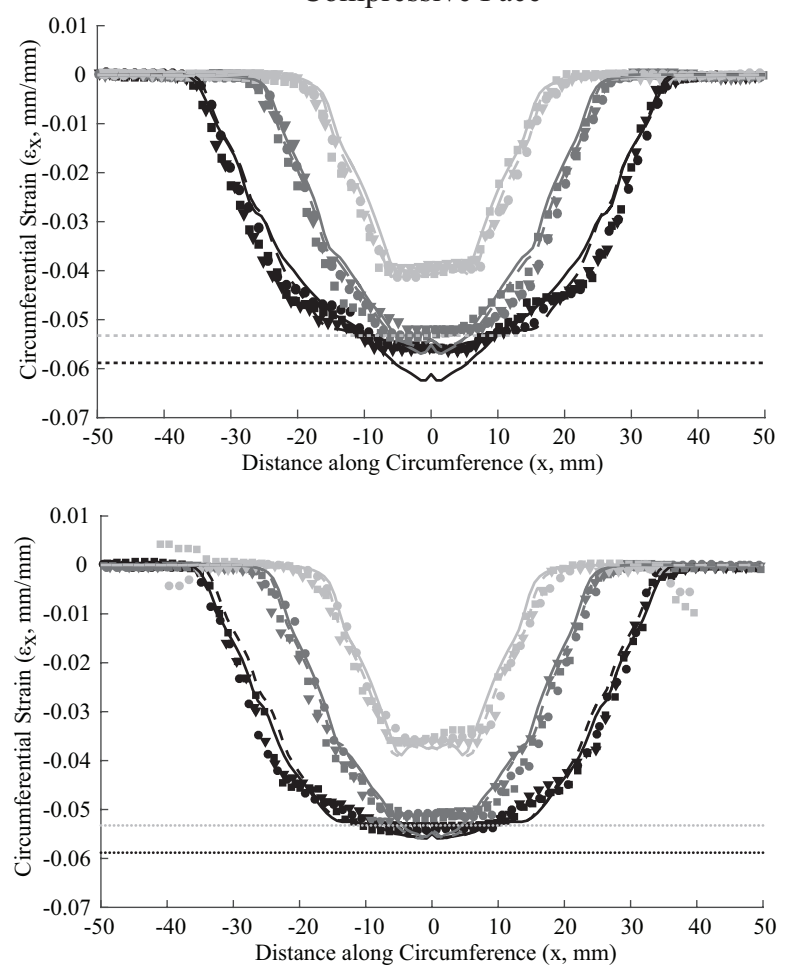

........ Analytical, 0\% NA Shift .... Analytical, 5\% NA Shift

Figure 5: Measured (Meas.), FE numerical, and analytical circumferential strain $\left(\epsilon_{x}\right)$ at longitudinal midline $(z=0 \mathrm{~mm})$ as a function of distance along the circumference $(x$, where the transverse midline corresponds to $x=0 \mathrm{~mm}$ ) for the tensile (left) and compressive (right) faces of $76.2 \mathrm{~mm}(3 \mathrm{in}$.) wide (top) and $203 \mathrm{~mm}$ (8 in.) wide (bottom) samples. All data shown is for plates with $t=12.7 \mathrm{~mm}$ (0.5 in). Measured DIC data includes three plate samples for each configuration, each indicated by a different marker type. 
$\mathrm{w}=76.2 \mathrm{~mm}$
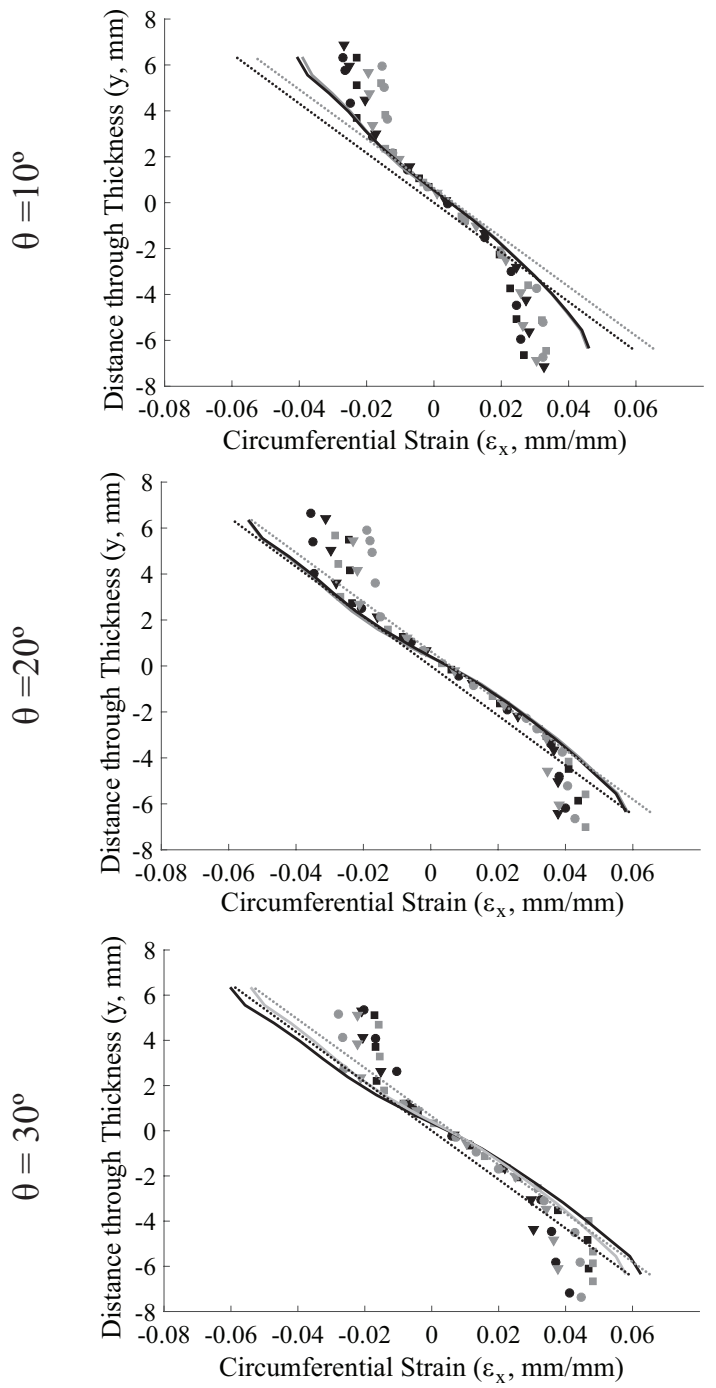

$\mathrm{W}=203 \mathrm{~mm}$
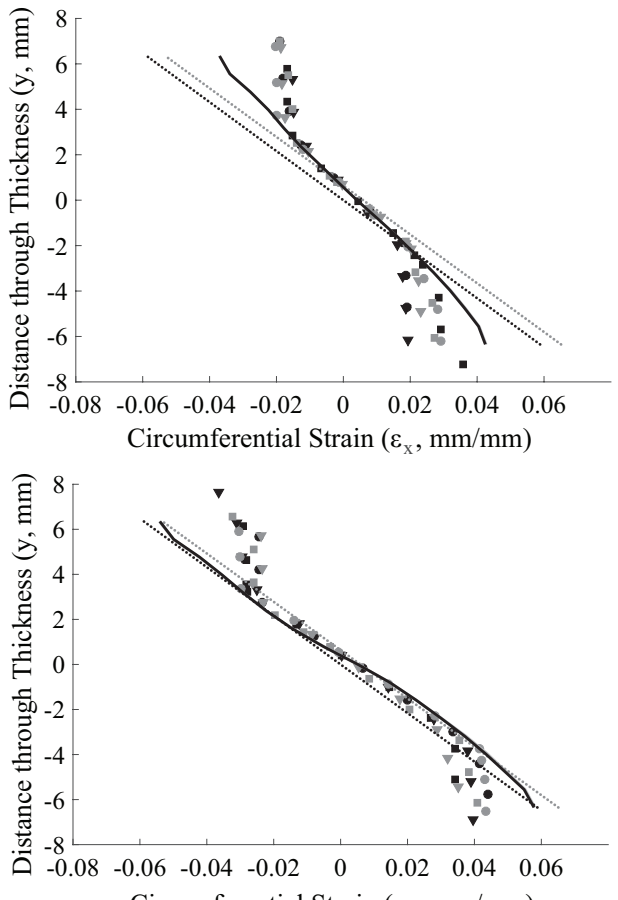

Circumferential Strain $\left(\varepsilon_{\mathrm{x}}, \mathrm{mm} / \mathrm{mm}\right)$

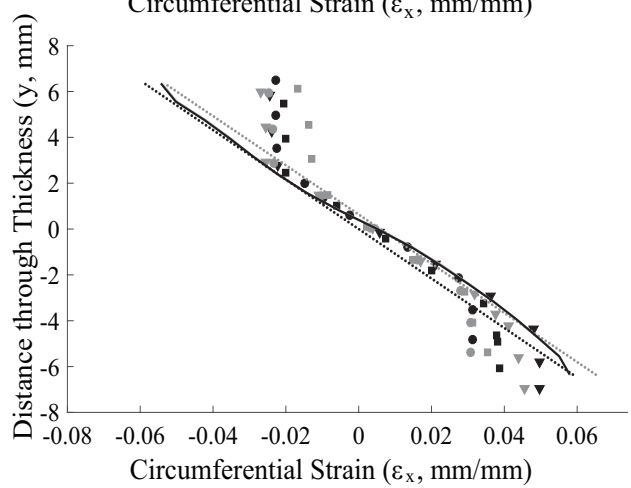

........... Analytical ( $0 \%$ NA Shift) -Analytical (5\% NA Shift)

Figure 6: Measured (Meas.), FE numerical, and analytical circumferential strain $\left(\epsilon_{x}\right)$ at plate edge $(z= \pm w / 2)$ as a function of distance along the thickness ( $y$, where the centerline corresponds to $y=0 \mathrm{~mm}$ ) for the 76.2 $\mathrm{mm}$ (3 in.) wide (left) and $203 \mathrm{~mm}$ ( 8 in.) wide (right) plates bent to $\theta=10^{\circ}$ (top), $\theta=20^{\circ}$ (middle), and $\theta=30^{\circ}$ (bottom). All data shown is for plates with $t=12.7 \mathrm{~mm}(0.5 \mathrm{in})$. Measured DIC data includes three plate samples for each configuration, each indicated by a different marker type, as well as both sides of each sample, as indicated by grayscale. 


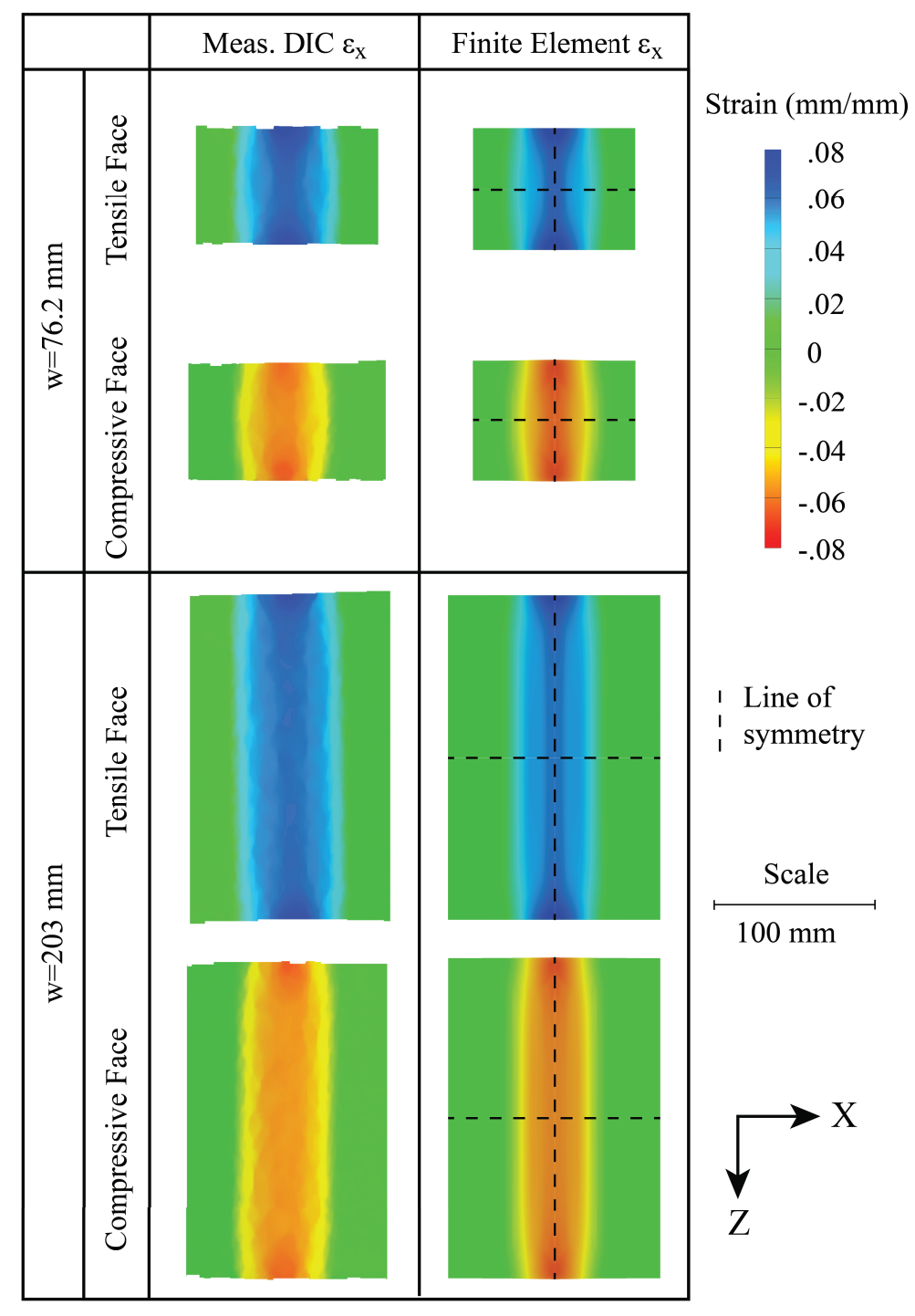

Figure 7: Plan view of measured (Meas., left) and 3D FE numerical (right) circumferential strain $\left(\epsilon_{x}\right)$ fields for $76.2 \mathrm{~mm}$ (3 in.) wide (top) and $203 \mathrm{~mm}$ ( 8 in.) wide (bottom) plates bent to $\theta=30^{\circ}$. All data shown is for plates with $t=12.7 \mathrm{~mm}(0.5 \mathrm{in})$. Dashed lines indicate planes where symmetry was employed to reduce computational expense of FE models. 


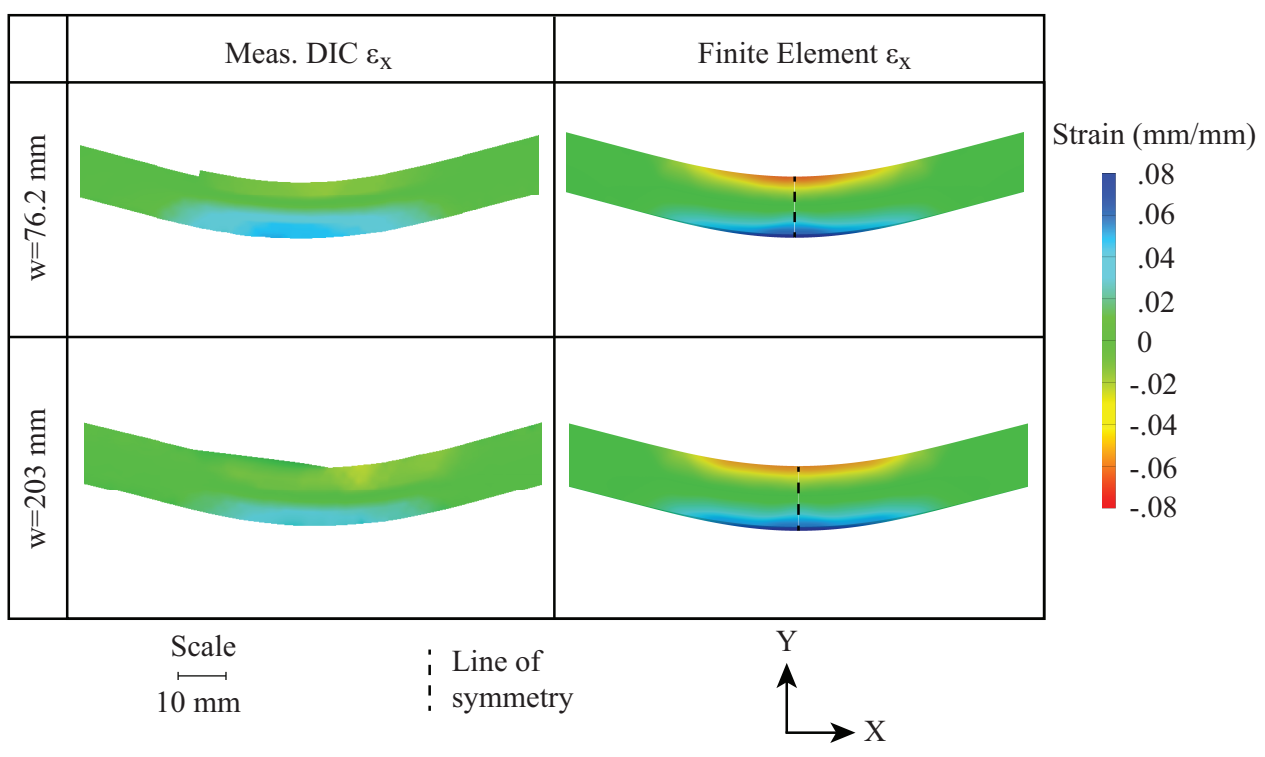

Figure 8: Elevation (side) view of measured (Meas., left) and 3D FE numerical (right) circumferential strain $\left(\epsilon_{x}\right)$ fields for $76.2 \mathrm{~mm}$ (3 in.) wide (top) and $203 \mathrm{~mm}$ ( 8 in.) wide (bottom) plates bent to $\theta=30^{\circ}$. All data shown is for plates with $t=12.7 \mathrm{~mm}$ ( $0.5 \mathrm{in})$. Dashed lines indicate planes where symmetry was employed to reduce computational expense of $\mathrm{FE}$ models. 


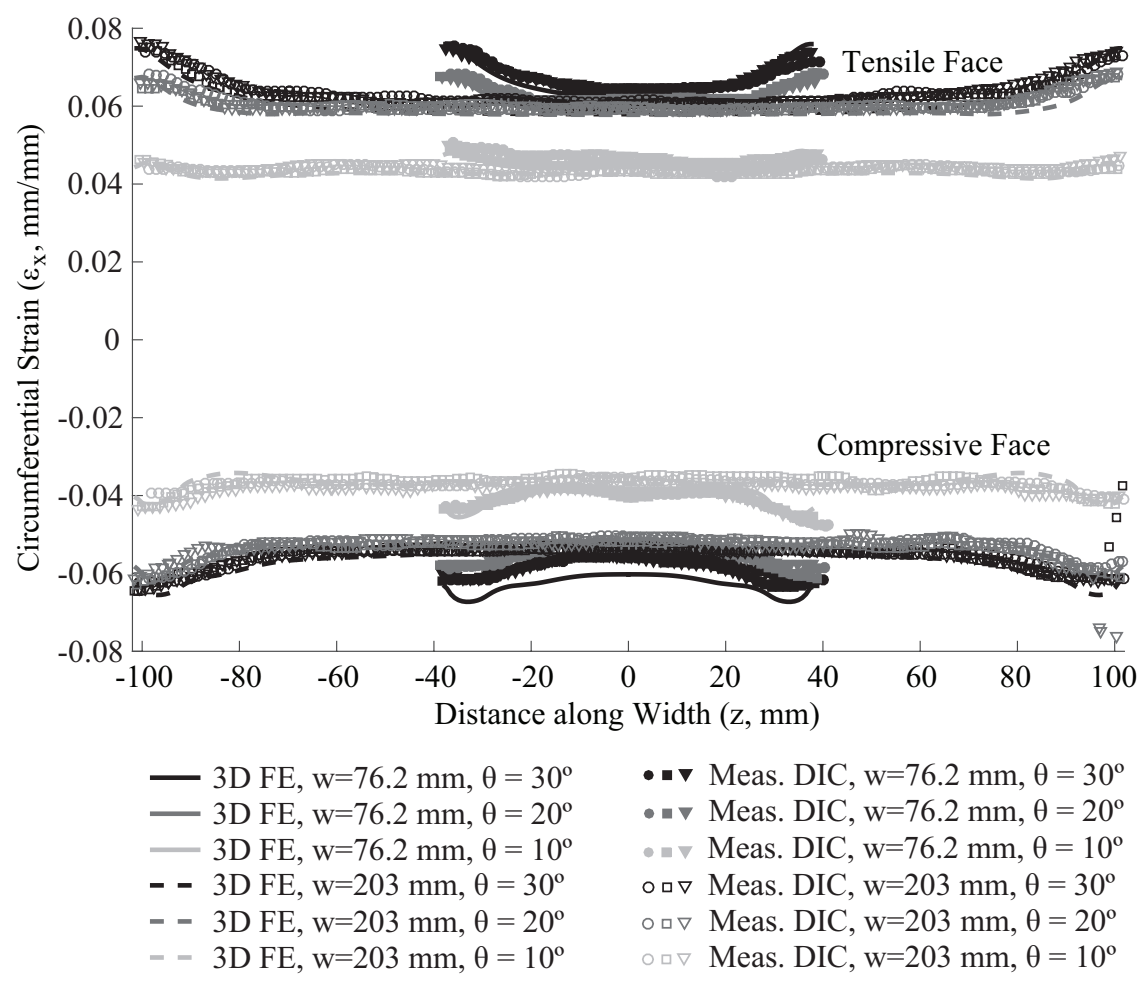

Figure 9: Measured (Meas.) and 3D FE numerical circumferential strain $\left(\epsilon_{x}\right)$ at the transverse midline $(x=0$ $\mathrm{mm})$ as a function of distance along the width ( $z$, where the longitudinal midline corresponds to $z=0 \mathrm{~mm}$ ) for the tensile and compressive faces of $76.2 \mathrm{~mm}$ (3 in.) wide and $203 \mathrm{~mm}(8 \mathrm{in}$.) wide samples. All data shown is for plates with $t=12.7 \mathrm{~mm}$ ( $0.5 \mathrm{in})$. Measured DIC data includes three plate samples for each configuration, each indicated by a different marker type. 

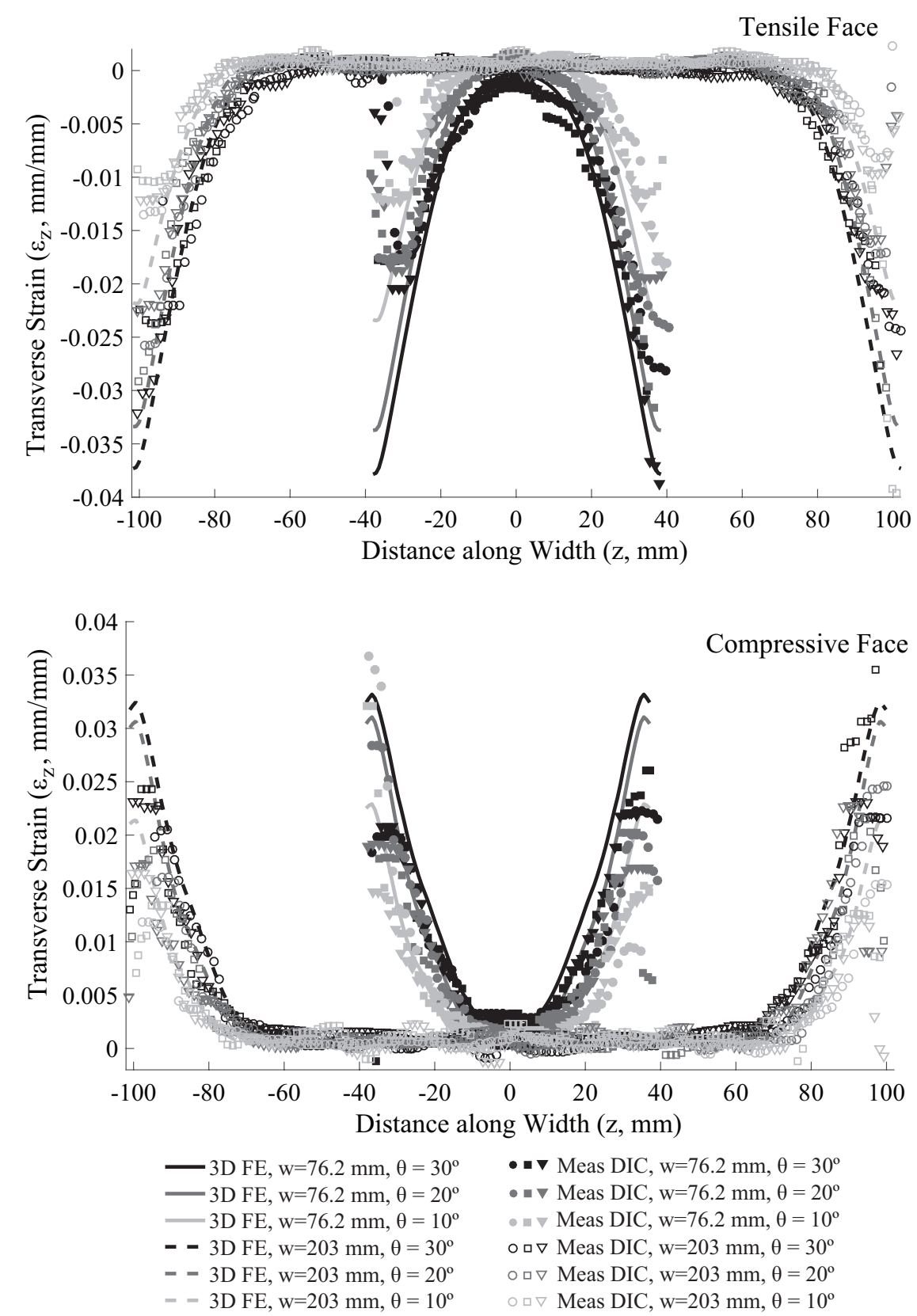

$\bullet \nabla$ Meas DIC, $w=76.2 \mathrm{~mm}, \theta=30^{\circ}$

- $\nabla$ Meas DIC, $w=76.2 \mathrm{~mm}, \theta=20^{\circ}$

$\because \nabla$ Meas DIC, $w=76.2 \mathrm{~mm}, \theta=10^{\circ}$

$\circ \square \nabla$ Meas DIC, $w=203 \mathrm{~mm}, \theta=30^{\circ}$

$\circ \square$ Meas DIC, $w=203 \mathrm{~mm}, \theta=20^{\circ}$

$\circ \square$ Meas DIC, $w=203 \mathrm{~mm}, \theta=10^{\circ}$

Figure 10: Measured (Meas.) and 3D FE numerical transverse strain $\left(\epsilon_{z}\right)$ at the transverse midline $(x=0$ $\mathrm{mm}$ ) along the width ( $z$, where the longitudinal midline corresponds to $z=0 \mathrm{~mm}$ ) for the tensile (top) and compressive (bottom) faces of $76.2 \mathrm{~mm}$ (3 in.) wide and $203 \mathrm{~mm}$ (8 in.) wide samples. All data shown is for plates with $t=12.7 \mathrm{~mm}(0.5 \mathrm{in})$. Measured DIC data includes three plate samples for each configuration, each indicated by a different marker type. 


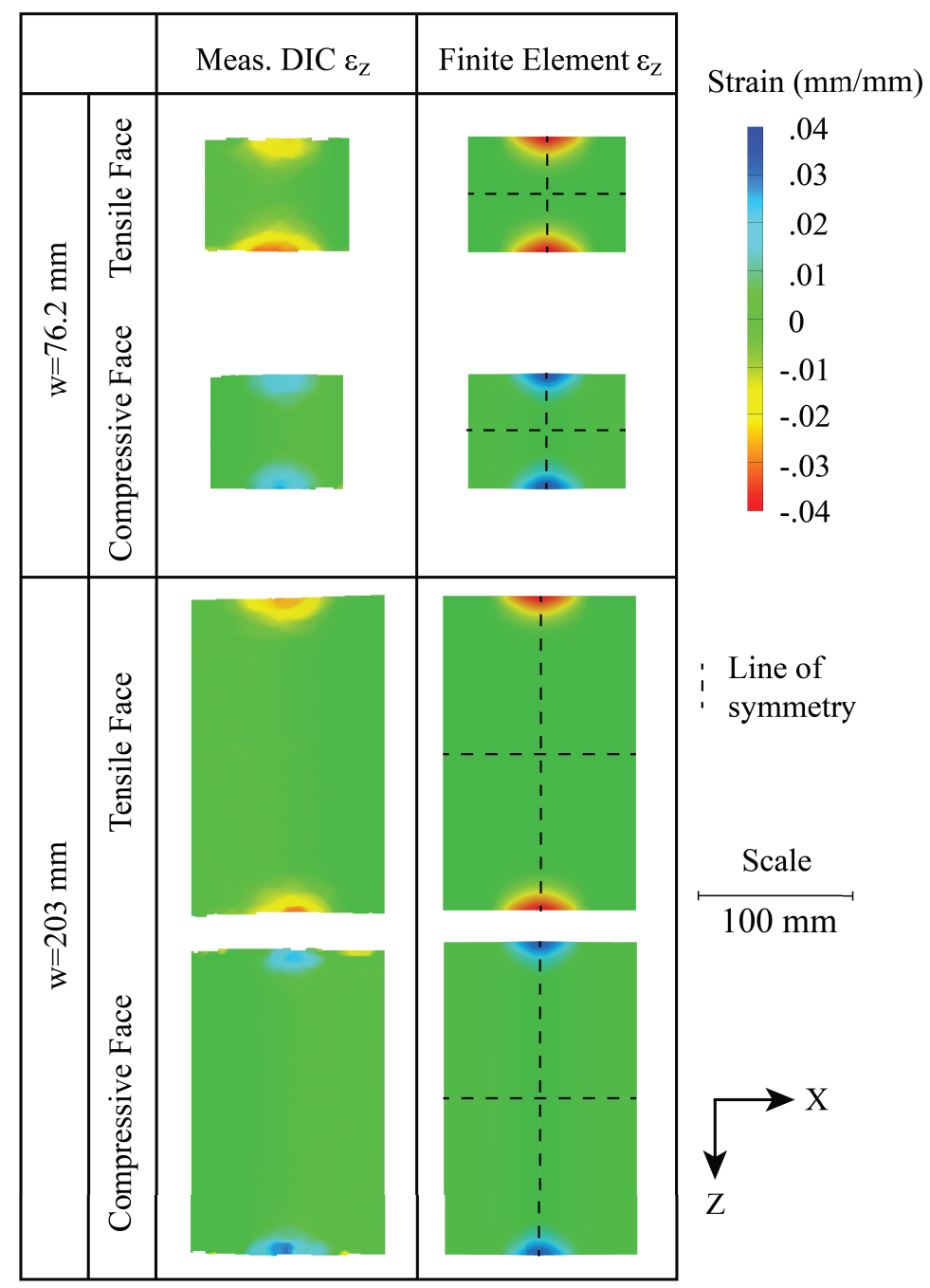

Figure 11: Plan view of measured (Meas., left) and 3D FE numerical (right) transverse strain $\left(\epsilon_{z}\right)$ fields for $76.2 \mathrm{~mm}$ ( 3 in.) wide (top) and $203 \mathrm{~mm}$ ( $8 \mathrm{in}$.) wide (bottom) plates bent to $\theta=30^{\circ}$. All data shown is for plates with $t=12.7 \mathrm{~mm}(0.5 \mathrm{in})$. Dashed lines indicate planes where symmetry was employed to reduce computational expense of FE models. 


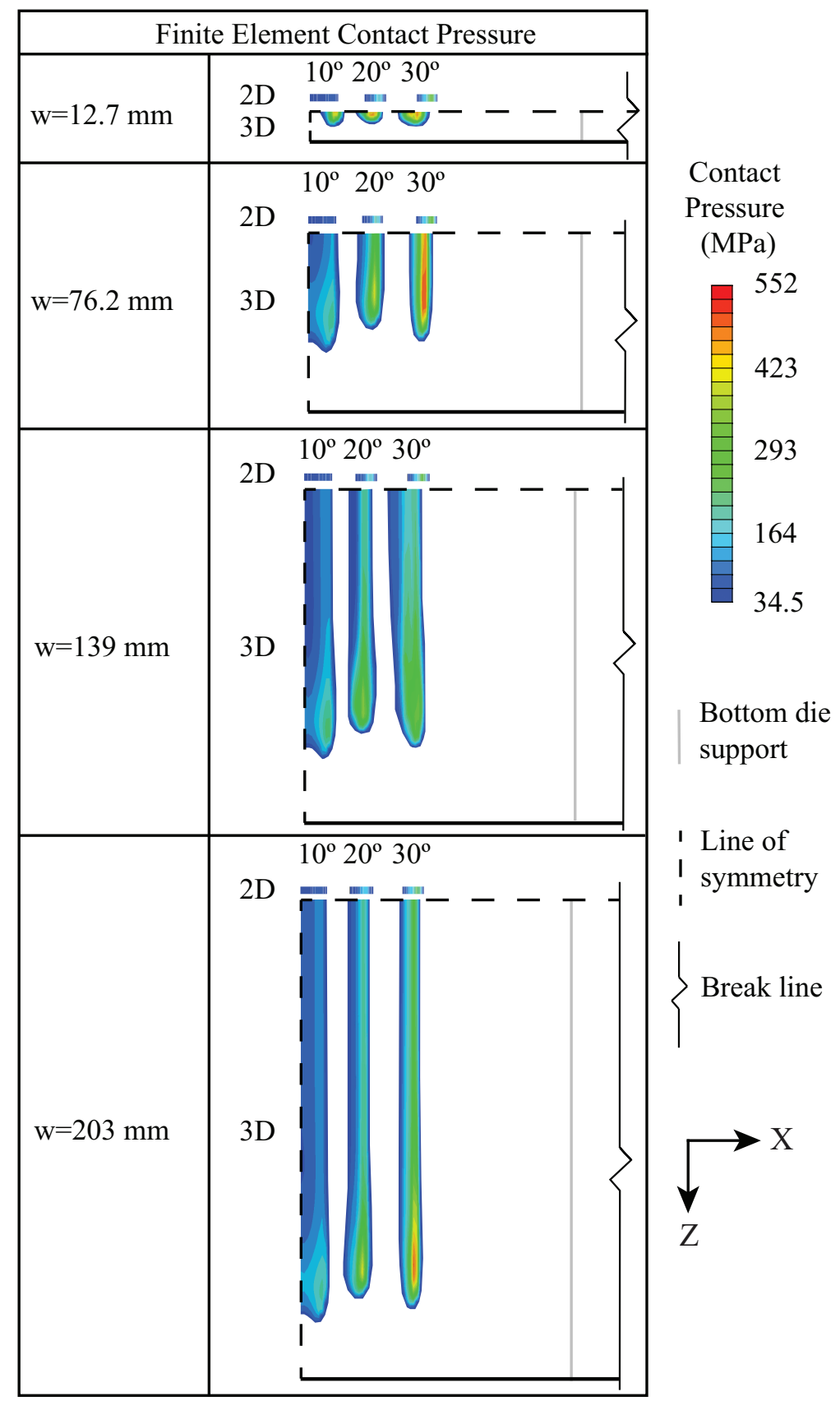

Figure 12: Plan view of 2D and 3D FE numerical predictions for progression of contact pressure on the compressive face with various bend angles and width of plates. 2D FE contact pressures are shown as thick lines above the 3D FE results for each case. Area shown for each case is the area with pressures above $34.5 \mathrm{MPa}$ (5 ksi), which was considered to be a lower bound pressure indicating contact. All data shown is for plates with $t=12.7 \mathrm{~mm}$ (0.5 in.). Dashed lines indicate planes where symmetry was employed to reduce computational expense of 3D FE models. Gray line indicates relative position of bottom die support for reference. 


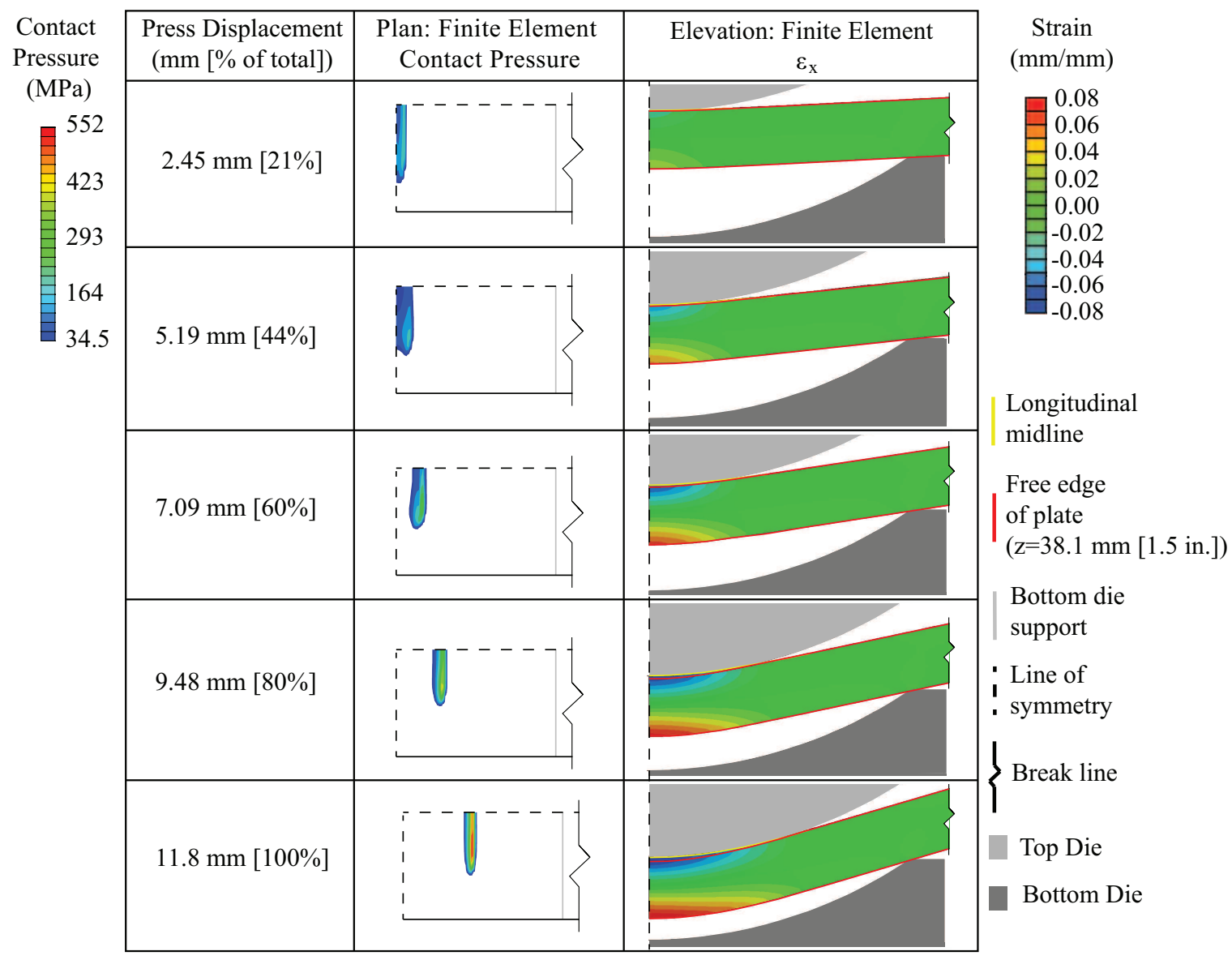

Figure 13: Plan and elevation views of 3D FE numerical predictions for progression of contact pressure and circumferential strain $\left(\epsilon_{x}\right)$ with respect to press displacement. All data shown is for plates with $t=12.7 \mathrm{~mm}$ (0.5 in.), $w=76.2 \mathrm{~mm}$ (3 in.) bent to $\theta=30^{\circ}$. Press displacement indicates the downward movement of the top die (light gray shaded area), where the bottom die (dark gray shaded area) is held fixed. Dashed lines indicate planes where symmetry was employed to reduce computational expense of 3D FE models. Gray line indicates relative position of bottom die support for reference. Yellow lines indicate the profile of the plate at the longitudinal midline $(z=0 \mathrm{~mm})$. Red lines indicate the profile of the plate at the free edge $[z=102$ $\mathrm{mm}(4 \mathrm{in})$.$] .$ 


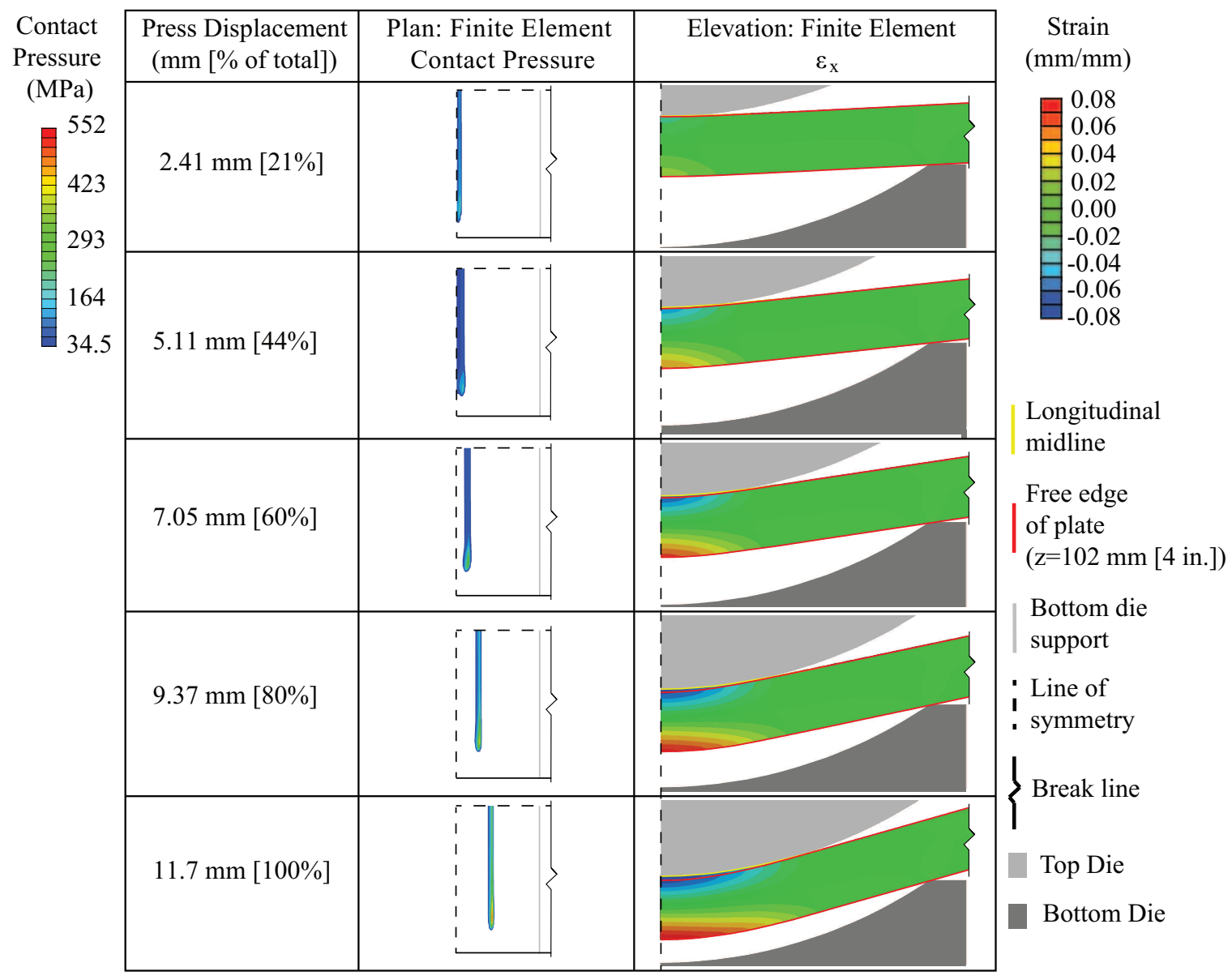

Figure 14: Plan and elevation views of 3D FE numerical predictions for progression of contact pressure and circumferential strain $\left(\epsilon_{x}\right)$ with respect to press displacement. All data shown is for plates with $t=12.7 \mathrm{~mm}$ ( 0.5 in.), $w=203 \mathrm{~mm}$ ( 8 in.) bent to $\theta=30^{\circ}$. Press displacement indicates the downward movement of the top die (light gray shaded area), where the bottom die (dark gray shaded area) is held fixed. Dashed lines indicate planes where symmetry was employed to reduce computational expense of 3D FE models. Gray line indicates relative position of bottom die support for reference. Yellow lines indicate the profile of the plate at the longitudinal midline $(z=0 \mathrm{~mm})$. Red lines indicate the profile of the plate at the free edge $[z=102$ $\mathrm{mm}(4$ in.)]. 


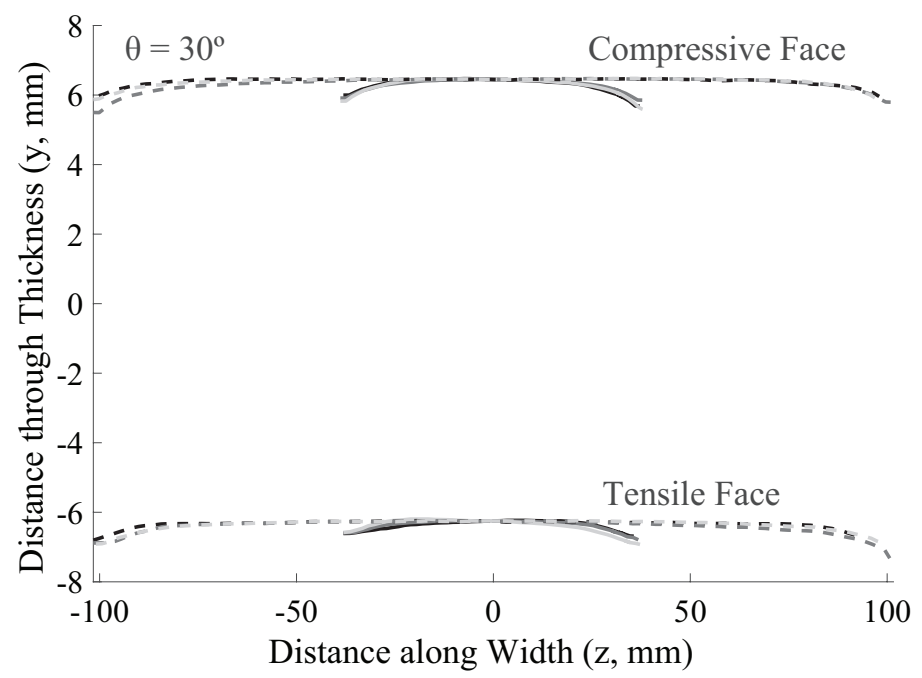

Meas. DIC, $w=76.2 \mathrm{~mm}$, Plate $1--$ Meas. DIC, $\mathrm{w}=203 \mathrm{~mm}$, Plate 1
Meas. DIC, $\mathrm{w}=76.2 \mathrm{~mm}$, Plate $2--$ Meas. DIC, $\mathrm{w}=203 \mathrm{~mm}$, Plate 2
Meas. DIC, $\mathrm{w}=76.2 \mathrm{~mm}$, Plate $3--$ Meas. DIC, $\mathrm{w}=203 \mathrm{~mm}$, Plate 3

Figure 15: Measured (Meas.) deformed shape at the transverse midline $(x=0 \mathrm{~mm})$ along the width $(z$, where the longitudinal midline corresponds to $z=0 \mathrm{~mm}$ ) of plates bent to $\theta=30^{\circ}$. All data shown is for plates with $t=12.7 \mathrm{~mm}(0.5 \mathrm{in})$. 

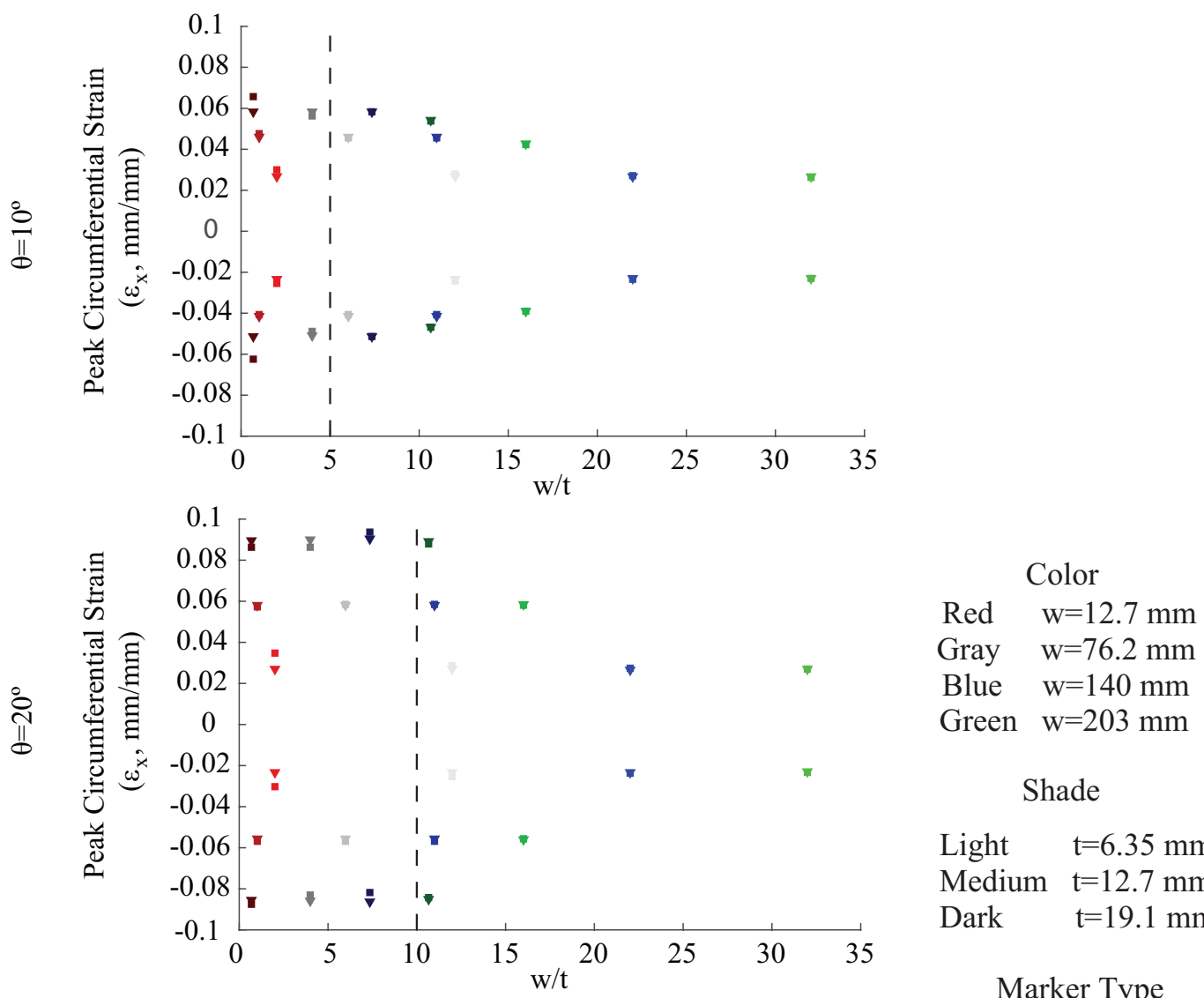

$\begin{array}{ll}\text { Light } & \mathrm{t}=6.35 \mathrm{~mm} \\ \text { Medium } & \mathrm{t}=12.7 \mathrm{~mm} \\ \text { Dark } & \mathrm{t}=19.1 \mathrm{~mm}\end{array}$

Marker Type

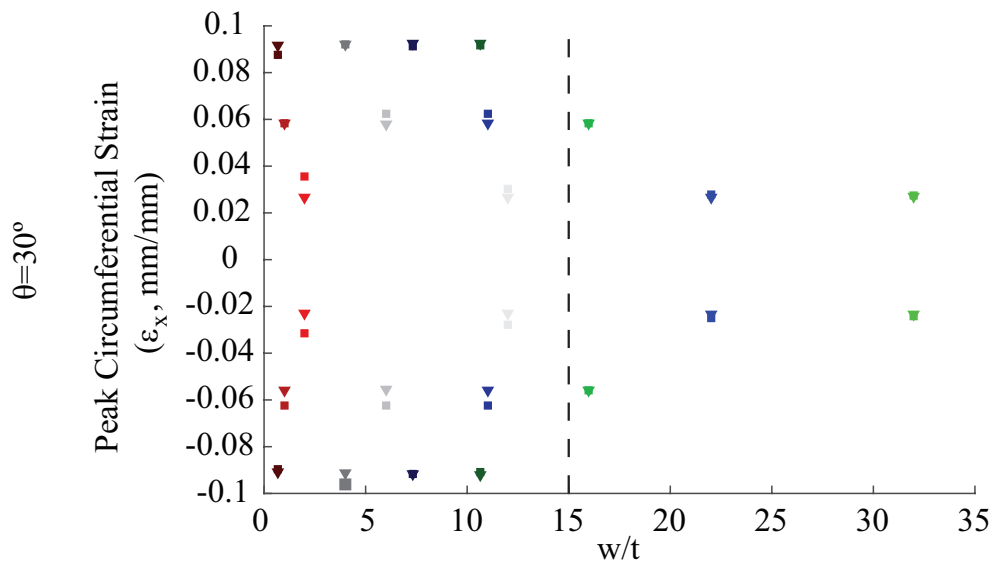

- 3D FE Model

$\checkmark$ 2D FE Model

w/t Ratio Threshold

Figure 16: 2D and 3D FE numerical peak circumferential strain $\left(\epsilon_{x}\right)$ as a function of width to thickness ratio $(w / t)$. Vertical dashed line indicates approximate $w / t$ ratio above which $2 \mathrm{D}$ FE models agree very closely with 3D FE models. 


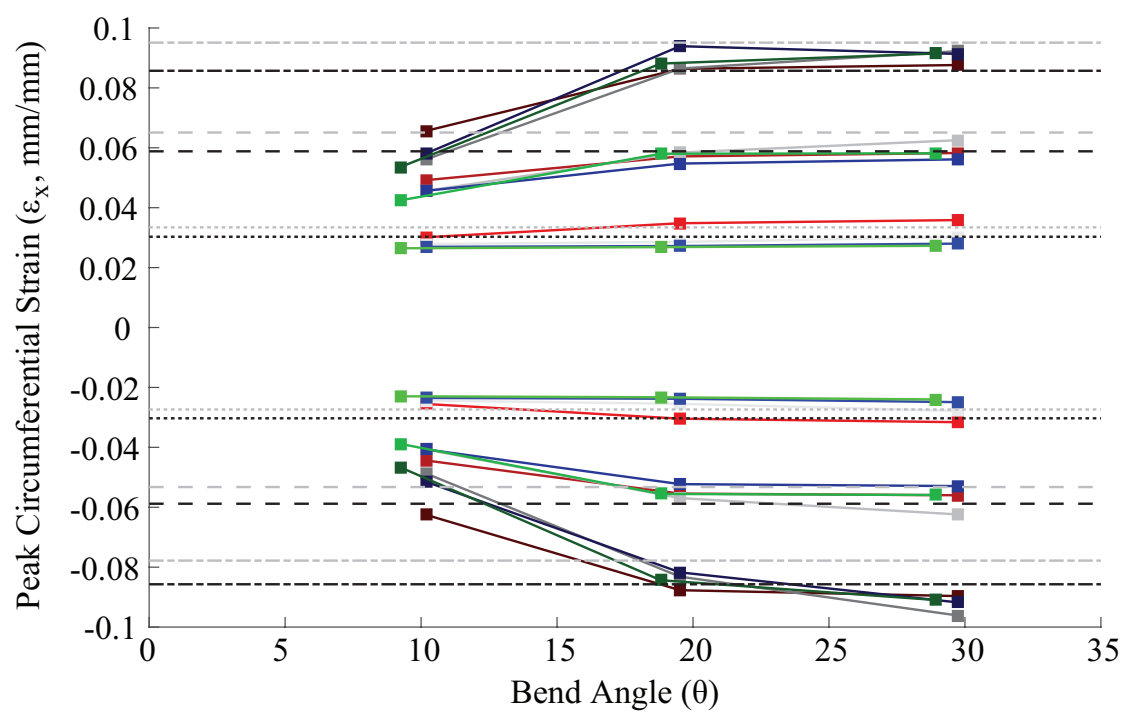

\begin{tabular}{|c|c|c|c|c|}
\hline \multicolumn{2}{|c|}{ Color } & \multicolumn{2}{|c|}{ Shade } & \multirow[b]{2}{*}{$\cdots \cdots . .$. Analytical $(\mathrm{t}=6.35 \mathrm{~mm}, 0 \% \mathrm{NA}$ Shift $)$} \\
\hline Red & $\mathrm{W}=12.7 \mathrm{~mm}$ & Light & $\mathrm{t}=6.35 \mathrm{~mm}$ & \\
\hline Gray & $\mathrm{w}=76.2 \mathrm{~mm}$ & Medium & $\mathrm{t}=12.7 \mathrm{~mm}$ & Analytical $(\mathrm{t}=6.35 \mathrm{~mm}, 5 \%$ NA Shift $)$ \\
\hline Blue & $\mathrm{w}=140 \mathrm{~mm}$ & Dark & $\mathrm{t}=19.1 \mathrm{~mm}$ & - - Analytical ( $\mathrm{t}=12.7 \mathrm{~mm}, 0 \% \mathrm{NA}$ Shift $)$ \\
\hline Green & $\mathrm{w}=203 \mathrm{~mm}$ & & & - - Analytical ( $\mathrm{t}=12.7 \mathrm{~mm}, 5 \% \mathrm{NA}$ Shift) \\
\hline & & & & ---- Analytical ( $\mathrm{t}=19.1 \mathrm{~mm}, 0 \%$ NA Shift) \\
\hline & & & & --- Analytical (t=19.1 mm, 5\% NA Shift) \\
\hline
\end{tabular}

Figure 17: 3D FE numerical and analytical peak circumferential strain $\left(\epsilon_{x}\right)$ along longitudinal midline $(z=0$ $\mathrm{mm})$ as a function of bend angle $(\theta)$. 

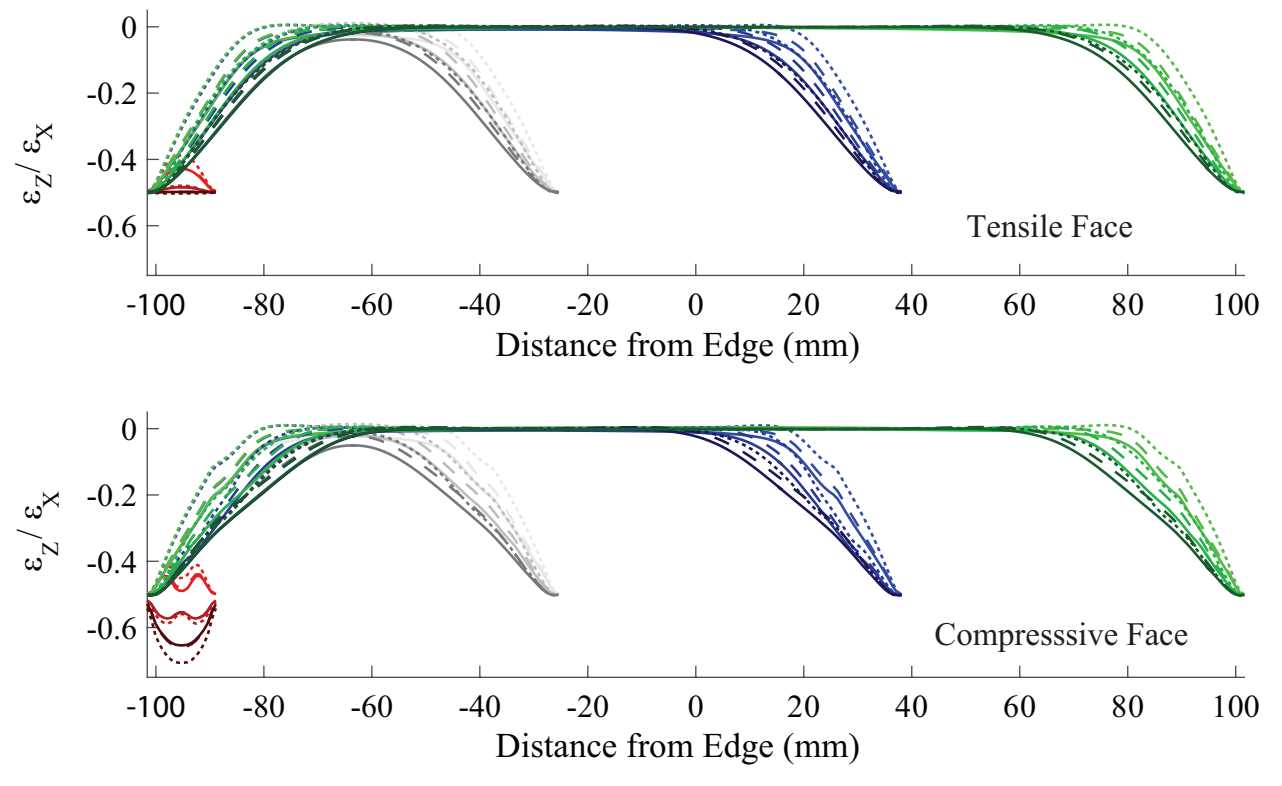

\begin{tabular}{|c|c|c|c|c|}
\hline Line type & & Color & Sh & de \\
\hline$\theta=30^{\circ}$ & Red & $\mathrm{w}=12.7 \mathrm{~mm}$ & Light & $\mathrm{t}=6.35 \mathrm{~mm}$ \\
\hline$-\theta=20^{\circ}$ & Gray & $\mathrm{w}=76.2 \mathrm{~mm}$ & Medium & $\mathrm{t}=12.7 \mathrm{~mm}$ \\
\hline$\theta=10^{\circ}$ & $\begin{array}{l}\text { Blue } \\
\text { Green }\end{array}$ & $\begin{array}{l}\mathrm{w}=140 \mathrm{~mm} \\
\mathrm{w}=203 \mathrm{~mm}\end{array}$ & Dark & $\mathrm{t}=19.1 \mathrm{~mm}$ \\
\hline
\end{tabular}

Figure 18: 3D FE numerical predictions for strain state $\left(\epsilon_{z} / \epsilon_{x}\right)$ at the transverse midline $(x=0 \mathrm{~mm})$ on the tensile (top) and compressive (bottom) faces. The horizontal axis indicates the distance from one edge. 


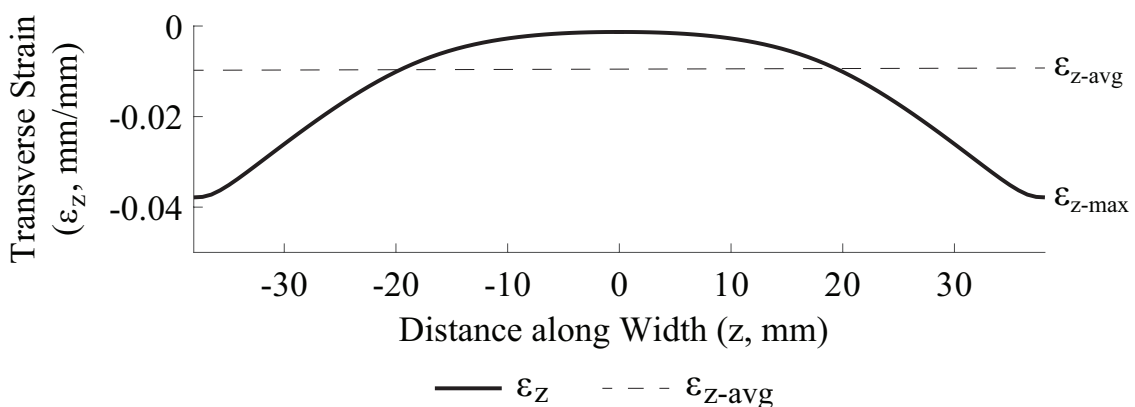

Figure 19: 3D FE numerical predictions for peak and average transverse strain $\left(\epsilon_{z}\right)$ at the transverse midline $(x=0 \mathrm{~mm})$ along the width $(z$, where the longitudinal midline corresponds to $z=0 \mathrm{~mm})$ on tensile face of $76.2 \mathrm{~mm}$ wide ( $3 \mathrm{in}$.) plate bent to $\theta=30^{\circ}$, with $t=12.7 \mathrm{~mm}(0.5 \mathrm{in})$. 

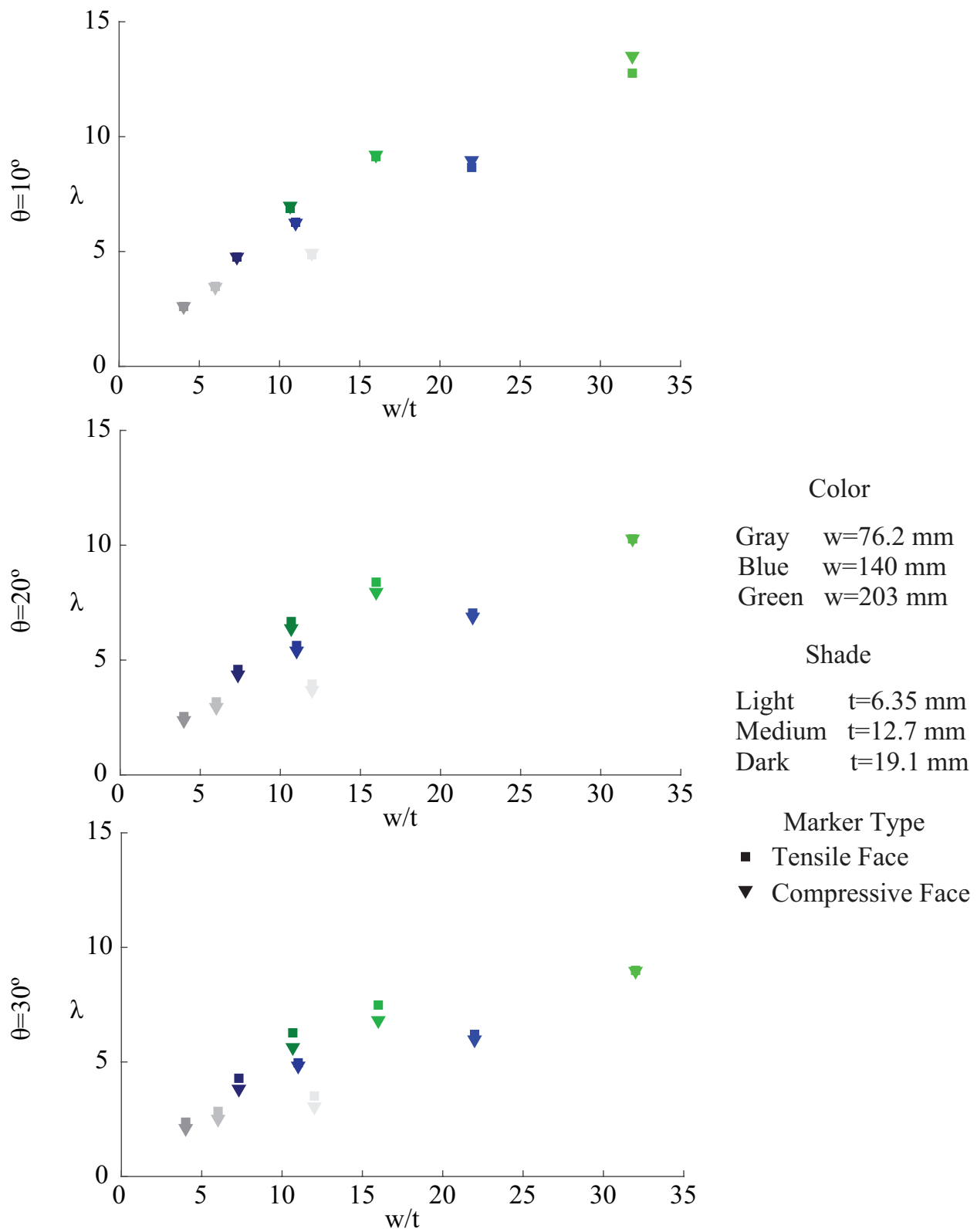

Figure 20: Relationship between $\lambda$ coefficients and width to thickness ratio $(w / t)$. 